\title{
La génesis del paisaje medieval en Álava: la formación de la red aldeana
}

\author{
Juan Antonio Quirós Castillo I
}

\begin{abstract}
RESUMEN
En este trabajo se realiza una síntesis sobre la evolución del territorio de Álava en la Alta Edad Media. En particular se defiende que la formación de una red de aldeas estables a partir del siglo VIII ha representado una cesura significativa en la evolución social del poblamiento alavés. Por este motivo se analiza, de forma sintética, los antecedentes de las aldeas, evidenciando como en torno al 450 se ha producido una profunda transformación de las formas de ocupación del espacio a favor de áreas marginales y en torno a nuevas pautas de jerarquización del territorio. La consolidación de nuevos poderes territoriales comporta la creación en torno al $750 \mathrm{ca}$. de una red de aldeas económicamente muy complejas, que han perdurado en su mayoría hasta nuestros días. Igualmente se detecta la existencia de formas de diferenciación social interna a partir de los siglos IX-X.
\end{abstract}

PALABRAS CLAVE: Aldea, Élites, Campesinos, Poblamiento, Alta Edad Media, castra.

\section{INTRODUCCION}

El presente texto no pretende ser sino una primera reflexión global sobre el territorio alavés en la Alta Edad Media en el marco de las investigaciones que está realizando en este terri-

\begin{abstract}
In this paper it is made a synthesis about the development of the territory of Alava in the High Middle Ages. In special, it is defended that the formation of a stable villages net from the VIII century on, has meant a meaningful cut in the social development of the settlement of Alava. For that reason it is analyzed, in a synthetic way, the antecedents of the villages, making clear that around the 450 it has been produced a deep transformation of the ways of space occupation in favour of the marginal areas and around new guidelines of territory hierarchies. The consolidation of new territorial powers involves the creation around the 750 of a net of economically very complex villages, that have remained in their majority until nowadays. Likewise it is detected the existence of inner social differentiation forms from the IX-X centuries on.
\end{abstract}

KEY WORDS: Village, Elites, Peasants, Settlement, High Middle Ages, Castra

torio el Área de Arqueología de la Universidad del País Vasco. Las líneas básicas de las que parte este trabajo están directamente relacionadas con las importantes aportaciones que, en los últimos años, algunos arqueólogos europeos están realizando en el análisis de la géne-

I Área de Arqueología. Departamento de Geografía, Prehistoria y Arqueología. Universidad del País Vasco / Euskal Herriko Unibertsitatea, C/ F. Tomás y Valiente s/n, 01006 Vitoria-Gasteiz. El presente trabajo ha sido realizado en el marco del proyecto de investigación BHA2002-04170-C05-05 financiado por la Dirección General de Investigación del Ministerio de Educación y Ciencia. La realización de este texto ha sido posible gracias al apoyo, la colaboración y la disponibilidad de numerosos arqueólogos e investigadores. En primer lugar quiero agradecer al Museo de Arqueología de Álava, y en particular a su directora, Amelia Baldeón, y a Elisa García Retes, el apoyo que están prestando al desarrollo de esta investigación y las facilidades que me han prestado para acceder a los datos de otras excavaciones. En segundo lugar debo agradecer al colega Javier Fernández Eraso que me facilitase el acceso a los materiales y a las cronologías radiocarbónicas, aún inéditas, de sus excavaciones realizadas en Los Husos. Igualmente con B. Bengoetxea Rementeria, F. Sáenz de Urturi, L. Gil Zubillaga, J. Fernández Bordegaray, F. Javier Ajamil Baños y todos los miem- 
sis de los paisajes medievales a partir de la sistematización del registro arqueológico (ZADORA RIO 2003; FRANCOVICH, HODGES 2003, VALENTI 2005; CHAVARRIA, BROGIOLO 2005; VIGIL ESCALERA 2006).

Esta renovación, que está articulando numerosos debates en los últimos años, descansa en la capacidad que han tenido estos autores en digerir y elaborar un volumen muy notable de registros materiales generados en el ámbito de la Arqueología de intervención y de investigación durante los últimos lustros, y en la clarividencia de haber formulado problemáticas y modelos explicativos autónomos y desvinculados de las producciones historiográficas. Tanto la cantidad como la calidad del registro arqueológico relativo a la Alta Edad Media europea está permitiendo proponer nuevos planteamientos historiográficos y cuestionar temáticas y modelos hasta el momento basados únicamente desde la documentación escrita ${ }^{2}$. Estamos, pues, ante una situación sin retorno de manera que la Historia de la Alta Edad Media no podrá hacerse sin recurrir de forma sistemática a la arqueología.

Una de las principales consecuencias de esta profunda renovación de los estudios sobre la Alta Edad Media ha sido sacar a la luz la existencia de formas de ocupación y explotación del espacio por parte de grupos de campesinos organizados en aldeas. Se trata de un registro material complejo, difícil de sistematizar y elaborar, pero aún más difícil de historiar ya que, como ha señalado E. Zadora Rio, el hábitat rural altomedieval difícilmente encuentra su lugar en los paradigmas históricos (ZADORA RIO 2003: 8).
En esta ocasión nuestro objetivo será el de presentar, de forma sintética, los resultados del estudio de un conjunto de aldeas altomedievales excavadas en el territorio alavés en los últimos diez años, que probablemente constituyen el conjunto numéricamente más significativo con el que contamos en la actualidad en el norte de la Península Ibérica, excluida Cataluña para los siglos VIII y X. La casi totalidad de estas excavaciones han sido realizadas por profesionales y empresas de arqueología en el contexto de la "Arqueología de intervención", de manera que aún no contamos con ninguna memoria definitiva de excavación. Sin embargo, gracias a las noticias recogidas en noticiarios arqueológicos como "Arkeoikuska" editado por el Gobierno Vasco y a las propias noticias proporcionadas por los arqueólogos profesionales, podemos realizar una primera caracterización e interpretación de este registro material. En un trabajo monográfico, actualmente en preparación, se pretende editar de forma amplia y adecuada estas intervenciones arqueológicas.

Como hemos dicho nuestro ámbito de observación será el territorio alavés, un espacio de $3.037,26 \mathrm{~km}^{2}$ enclavado en el sur del País Vasco, entre el Cantábrico y el Valle del Ebro. La artificiosidad que comporta elegir un "territorio histórico" actual ha de entenderse únicamente como un criterio práctico y de comodidad, aunque hay que ser consciente de que se trata de un espacio compartimentado y complejo que agrupa realidades distintas. En términos geográficos podemos diferenciar al menos cinco espacios; la tierra de Ayala, correspondiente al alto valle del Nervión, que es una comarca cantábrica; el territorio montañoso oriental; la Llanada central y sus rebordes montañosos; Treviño y la Rioja alavesa.

\footnotetext{
bros de Ondare he podido discutir aspectos básicos tratados en este trabajo, poniéndome a disposición datos y materiales inéditos. En la actualidad se prepara con estos últimos una obra de síntesis sobre las aldeas alavesas de los siglos VIII-XI. Agradezco a A. Vigil Escalera, I. Martín Viso, E. Pastor, J. J. Larrea, A. Alonso y E. Alfaro sus comentarios que han contribuido a mejorar el texto.

2 "Alla luce di tale stato di cose, è utile tornare ad una lettura delle fonti scritte attraverso i modelli elaborati sulla base di quelle archeologiche, capovolgendo quando è stato proposto in sede storiografica, vale a dire che "le poche fonti materiali" relative al periodo compreso tra la fine del VII e l'inizio del S secolo debbano "ancora essere lette attraverso le fonti scritte", a causa dell'esiguità delle conoscenze conseguite su base archeologica. Quindi dobbiamo verificare se un sistema insediativo fondato sul villaggio, che emerge chiaramente dalle indagini sul campo, risulti o meno compatibili con i documenti disponibili per l'alto medioevo" (FRANCOVICH 2004, p. $X X)$.
} 
Se trata de un territorio que cuenta con una importante tradición de estudios históricos, ya que en el conjunto del País Vasco es un espacio privilegiado para el estudio de la Alta Edad Media. Los cartularios de instituciones religiosas como San Millán de la Cogolla, Valpuesta, Oña, etc. documentan, en ocasiones de forma detallada, la sociedad alavesa de los siglos VIIIX (GARCÍA DE CORTAZAR 1983).

Sin embargo, el registro arqueológico aún no ha sido utilizado en toda su potencialidad para historiar este período. No obstante, las aportaciones recientes que están realizando tanto los arqueólogos profesionales ya mencionados, así como investigadores entre los que hay que mencionar el Grupo de Arqueología de la Arquitectura de la Universidad del País Vasco, están cambiando rápidamente este panorama. Entre los principales indicadores hay que señalar la existencia de un conjunto notable de dataciones radiocarbónicas de yacimientos tardoantiguos y altomedievales relativos al territorio alavés y su entorno más inmediato (fig. I).

El presente trabajo se estructurará esencialmente en tres partes; en primer lugar se analizará brevemente la temática de la arqueología de las aldeas; a continuación se trazarán las líneas básicas de las transformaciones del espacio alavés en el período comprendido entre la caída del Imperio Romano y la formación de las aldeas; para concluir se analizarán las aldeas altomedievales excavadas hasta el momento y se planteará una interpretación general del fenómeno.

Antes de concluir esta introducción querríamos señalar que nuestro análisis se ha basado esencialmente en el estudio de las estructuras de poblamiento, ya que desde nuestro punto de vista constituyen los principales indicadores de los que disponemos en la actualidad para realizar una historia social del territorio alavés en la Alta Edad Media. Por este motivo se ha preferido en esta ocasión no abordar de forma específica los poblados de los muertos, teniendo en cuenta que cuenta con excelentes síntesis recientes (AZKARATE 2004).

\section{LAS ALDEAS DE LOS HISTORIADORES Y DE LOS ARQUEOLOGOS}

Con este sugestivo título hace diez años E. Zadora Rio planteaba, en el contexto de la historiografía francesa, la contradicción que se había venido a crear entre el concepto de aldea que había construido la historiografía, frente a los resultados de las excavaciones de los asentamientos concentrados altomedievales (ZADORA RIO 1995).

Efectivamente, durante los años 70 y 80 la historiografía francesa había logrado situar en el centro del debate sobre la formación de la sociedad feudal las transformaciones que se habían producido en los paisajes y las estructuras de poblamiento. Tanto a través de análisis territoriales específicos, como el realizado por P. Toubert en el Lacio (TOUBERT 1973), como a través de síntesis más globales, como las realizadas por O. Chapelot y R. Fossier (1980) integrando el registro material y documental a la hora de analizar las estructuras del poblamiento en el centro y norte europeo, o la firmada por este último autor (FOSSIER 1984) en torno a la formación de Europa, el análisis social de las transformaciones del poblamiento constituyeron un eje fundamental para la creación de nuevos paradigmas interpretativos. Si Toubert centra su atención en la génesis de los castillos, Fossier se focaliza en el surgimiento de las aldeas. Para este último autor la Alta Edad Media se caracterizaría por un poblamiento disperso formado por "pueblos efímeros" caracterizados por una "sedentarización imperfecta" asociados a un sistema productivo basado en una agricultura itinerante e inestable. Solamente en torno al año mil se habría producido la formación de las aldeas en el marco del "enceldamiento" o "revolución feudal" que habría comportado la sujeción del campesinado a los poderes señoriales y la reordenación autoritaria de la producción y de las formas de poblamiento. Es en el siglo XI cuando nacen las aldeas en torno al cementerio, la parroquia, los castillos y los señoríos, que constituyen los marcos de sociabilidad en torno a los cuales se reorganiza la sociedad medieval como resultado de la afirmación del feudalismo (FOSSIER 1982: 190 ss; FOSSIER 1996: 210 ss). De esta 
manera Fossier dota al concepto de aldea de un significado sociológico, que va más allá del carácter agrupado del poblamiento y se dota de contenido político e ideológico muy concreto.

Esta propuesta interpretativa, que va a influir notablemente en el desarrollo de la Arqueología Medieval francesa (PEYTREMANN 2003, p. 25-102), va asimismo a trascender a otras corrientes historiográficas europeas, y concretamente en el caso de la Península Ibérica su influencia, adecuadamente filtrada y releída a la luz de las "obsesiones historiográficas" locales, ha sido muy notable.

Ya en la misma formulación de la propuesta de "organización social del espacio" que realiza García de Cortazar en el año 1985 se atribuye a la historia del poblamiento un papel central a la hora de historiar la sociedad altomedieval, de tal manera que aún en ausencia de documentación arqueológica adecuada, se analiza en la documentación escrita la historia del poblamiento. Más concretamente, la creación de una red de aldeas en torno al año mil constituye un elemento significativo a la hora de comprender la organización social del espacio entre el Cantábrico y el Duero (GARCíA DE CORTAZAR 1985: 70-7I). Es cierto que este autor subraya asimismo las particularidades del espacio peninsular, señalando posteriormente que no estaríamos en presencia de una concentración autoritaria del poblamiento en los siglos X-XIl, ya que el proceso de afirmación de la aldea como modelo hegemónico de organización social se habría producido en el período comprendido entre el 850-950 (GARCÍA DE CORTAZAR 1988, p. 22).

Esta propuesta interpretativa ha influido notablemente en el medievalismo español, tanto a través de la creación de una escuela propia (p.e. PEÑA BOCOS 1995), como a través del reconocimiento de una estrategia de análisis social del paisaje que ha incidido notablemente en la evolución reciente de la historiografía. Este mismo autor, en uno de sus trabajos de síntesis historiográfica realizados en los últimos años ha subrayado cómo el debate en torno a la transición entre el mundo antiguo y el medieval ha pasado sucesivamente de analizar primero la población, después la sociedad y por último el poblamiento, de tal manera que este último se ha convertido en el "fósil director" de una organización social del espacio (GARCÍA DE CORTAZAR 1999: 506 ss).

A este propósito no puede dejar de señalarse la notable aportación en términos teóricos que supuso el trabajo de M. Barceló a finales de los años 80, cuando publica su "reflexión métodica" sobre la Arqueología Medieval. Este autor analiza desde un sólido aparato conceptual, temáticas y aspectos claves que permiten comprender el significado último del proceso de concentración campesina en términos de organización autoritaria de la producción y de captura de excedentes en términos señoriales (BARCELÓ 1988: 197-202). Propone para ello la necesidad de realizar una arqueología "refundada" de las sociedades medievales, que preste una atención prioritaria a los espacios de cultivo que no ha tenido, sin embargo, la atención que habría merecido (BARCELÓ 1995).

Pero ha sido en los años 90 cuando el poblamiento se ha convertido decididamente en la historiografía del norte peninsular en el indicador básico para comprender el tránsito entre el mundo antiguo al medieval. Toda una serie de trabajos atribuidos a distintas "escuelas" han incorporado durante estos años la génesis de los paisajes medievales y de las estructuras aldeanas en las agendas de investigaciones. Algunos autores han abrazado explícitamente (MARTÍN VISO 2000: 137-139) o implícitamente (ESCALONA 2002: 223, GARCÍA CAMINO 2002: 335) el concepto de aldea trazado por la historiografía francesa, aunque desde planteamientos distintos; en cambio, otras propuestas aceptan la existencia de una red aldeana en torno al año mil como resultado de la existencia de un largo proceso de "crecimiento agrario" que se desarrollaría entre los siglos VIII, IX y X (PASTOR 1996: 64 ss; LARREA 1998: 323-326), desplazando de esta manera al período visigodo el modelo de poblamiento inestable y disperso que otros atribuyen a los siglos posteriores. Otros autores, por su parte, identifican la creación de las aldeas como un momento fundamental en la formación del paisaje medieval, aunque en ausencia de intervenciones arqueológicas 
no se les pueda atribuir la fecha de nacimiento (FERNÁNDEZ MIER 1999), mientras que en el caso de Galicia no se ha dado la prioridad al fenómeno de las aldeas sino más bien a "comunidades pseudos-monásticas" como agentes de transformación social (LÓPEZ QUIROGA 2004: 296) ${ }^{3}$.

En la base de estas diferencias tan significativas coexisten tanto aproximaciones teóricas diferentes del análisis social del paisaje, la ausencia de un registro arqueológico sistematizado y de calidad que permita abordar con claridad aquello que los documentos conservados no dicen, así como la dificultad en digerir y asumir lo que las propias excavaciones arqueológicas dicen (AZKARATE, QUIRÓS CASTILLO 200 I: 26).

Este no es, en todo caso, un problema únicamente exclusivo de la historiografía española, sino que se puede generalizar a otros sectores europeos. De hecho, a partir de los años 80 el desarrollo de la arqueología altomedieval francesa ha permitido reconocer la existencia de aldeas fechables antes del año mil que cuestionaban abiertamente el modelo propuesto de Fossier, como en el caso de Villiersle-Sec, Baillet-en-France, etc. Para resolver esta contradicción se acuña el concepto de protovillage, en un intento de armonizar el paradigma de Fossier con la existencia de aldeas anteriores al año mil (CUISINIER, GUADAGNIN 1988; COLARDELLE, VERDEL 1993: 379-382). Pero resulta evidente que esta contradicción no podía mantenerse, más aún cuando las sucesivas síntesis arqueológicas realizadas ya en los años 90 no solo planteaban la existencia de una densa red aldeana en amplios sectores franceses, sino que también sugerían la complejidad social que era posible leer en el seno de estas aldeas (LORREN, PÉRIN 1995, SCHNEIDER 1992). En los últimos años, mientras que los arqueólogos han desarrollo nuevas propuestas de análisis complejos de la sociedad altomedieval a través del estudio de las aldeas (BONIN 2000;
CATTEDDU 200 I; PEYTREMANN 2003), en parte de la historiografía francesa siguen radicados los planteamientos de R. Fossier, más aún tras el debate sobre la "mutación" feudal de los últimos años.

En estos mismos años la arqueología medieval italiana ponía en discusión el modelo de incastellamento de Toubert, al reconocer la existencia de una red aldeana altomedieval sobre la que se implantaban los castillos, de tal manera que estos últimos constituirían únicamente un episodio más -el más visible en los documentos- de una larga historia que se había iniciado siglos antes (FRANCOVICH, MILANESE 1989). Más recientemente la arqueología de las aldeas altomedievales en Italia se ha convertido en una temática fundamental en el análisis de la génesis de los paisajes medievales (BROGIOLO 2005), hasta el punto de convertirse para algunos autores en una indicador del inicio de la Edad Media, marcando una ruptura definitiva con el pasado romano (FRANCOVICH, HODGES 2003; VALENTI 2005).

Asimismo en el norte de Europa las síntesis recientes de autores como $\mathrm{H}$. Hamerow (2002) han reconocido una compleja evolución social a partir de la arqueología de las aldeas, en la que se han podido identificar transformaciones muy significativas en torno al siglo VIII como resultado de la reorganización y planificación de los espacios residenciales, la transformación de las prácticas agrarias y ganaderas y la creación de nuevas redes de intercambios que modificaron sustancialmente la estructura económica de las aldeas. Estas transformaciones en los espacios rurales se relacionan con una importante reordenación de las estructuras políticas y de la propiedad. Concluye la autora citada, subrayando que las comunidades rurales altomedievales organizadas en aldeas no eran simples, ni estaban aisladas económicamente, como se había planteado con anterioridad (HAMEROW 2002: 156-190).

3 Por brevedad, en esta ocasión no se han citado otras investigaciones recientes realizadas en torno al poblamiento altomedieval en el N Peninsular (ver en particular AA. W., 1998; BARRIOS, MARTíN VISO 2000-200 I,...), ya que se pretende volver sobre el argumento en otra sede. 
Podríamos finalizar por lo tanto afirmando que, mientras el modelo historiográfico trazado a finales de los años 70 e inicios de los 80 que asocia la génesis de las aldeas a la afirmación del feudalismo y al encuadramiento del campesinado en rígidos marcos señoriales sigue dominando, con variaciones sobre el tema, el discurso de los historiadores, la Arqueología ha desarrollado un registro complejo que aún no ha sido digerido ni asumido en las síntesis generales sobre la Alta Edad Media.

En el caso de la Península Ibérica la situación es aún más problemática debido, por un lado, a la dependencia de modelos interpretativos esculpidos a partir de influencias externas viciadas por la situación apenas descrita y, por otro, a la carencia de un registro arqueológico adecuado.

A esto hay que añadir que la arqueología de las aldeas y de los despoblados, base a partir de la cual se ha desarrollado en los últimos decenios la reciente Arqueología Medieval en toda Europa, no han tenido una buena acogida en la historia reciente de la Arqueología Medieval Española. En particular en el Norte de la Península Ibérica esta temática no ha sido prácticamente desarrollada, de tal manera que son muy escasos los ejemplos de despoblados y de aldeas medievales en los que se han analizado los espacios residenciales, privilegiando sustancialmente otras temáticas de carácter monumental, como las iglesias, las necrópolis o los centros fortificados. De hecho, salvo casos puntuales no se ha desarrollado una verdadera arqueología de las aldeas medievales. La ausencia de esta "desmonumentalización" de la Arqueología Medieval del Norte peninsular en los últimos 30 años ha tenido, desde nuestro punto de vista, efectos muy notables a la hora de avanzar en el desarrollo de modelos y propuestas teóricas de calado sobre el proceso de formación de los paisajes medievales - las sociedades feudales y de superar las contradicciones que existen entre los modelos históricos y el registro material. Con frecuencia este conflicto se ha resuelto leyendo el registro arqueológico con fórmulas deudoras de los modelos interpretativos generados desde la historiografía.
Urge, por ello, desde nuestro punto de vista, una revisión de las prioridades de investigación seguidas por la Arqueología Medieval en el norte peninsular, evitando seguir generando registros redundantes y poco significativos a favor de intervenciones de calidad que pongan su atención en el estudio de las aldeas medievales y de sus espacios productivos.

Este paso ya se ha dado en el caso de las aldeas de época visigoda de la meseta (VIGIL ESCALERA 2006), de tal manera que la sistematización de este registro está obligando a revisar aspectos básicos de la sociedad de los siglos VI y VII en este sector peninsular. Es necesario, por lo tanto, ampliar nuestro ámbito de observación, tanto en términos espaciales como cronológicos, con el fin de poder superar el impasse en el que actualmente nos encontramos tras las últimas aportaciones realizadas en torno al tránsito de la Antigüedad a la Edad Media en el norte peninsular (QUIRÓS CASTILLO, VIGIL ESCALERA 2006).

\section{LOS ANTECEDENTES DE LAS ALDEAS ALAVESAS}

Como hemos señalado con anterioridad, en esta ocasión se pretende abordar el proceso de formación de las aldeas alavesas a partir del siglo VIII, momento en el que se crea un paisaje plenamente medieval que prácticamente ha llegado hasta nuestros días (fig. 2).

Ante la ausencia de una síntesis orgánica sobre la historia social del poblamiento alavés que precede a la formación de las aldeas, se ha creído oportuno en esta ocasión plantear algunas de las principales problemáticas que caracterizan el período comprendido entre los siglos $\mathrm{V}$ y VIII como antecedente necesario para entender el proceso de formación de la red aldeana. Las siguientes notas, por lo tanto, no pretenden ni mucho menos agotar el tema, puesto que son muchos los yacimientos que aún están inéditos o de los que se conocen breves noticias publicadas en revistas como "Arkeoikuska", y son muchos los datos que aún no han sido procesados. Teniendo en cuenta estas cautelas, creo que es posible hacer una relec- 
tura original de algunas temáticas y problemas relativos a este territorio y confrontarlos con otros territorios peninsulares y europeos. Téngase en cuenta que no se pretende realizar más que una aproximación a cuestiones muy complejas que habrán de ser tratadas de forma más analítica en estudios de detalle.

Nuestro punto de partida habrá de ser el análisis del territorio alavés en época romana, período para el que contamos con síntesis recientes (GIL 1996; FILLOY, GIL 2000: 39-58).

Estas investigaciones muestran cómo es en torno al siglo I d. C. cuando se va a producir una verdadera transformación de las estructuras de poblamiento como resultado de la afirmación de un nuevo orden social. La primera ordenación ortogonal reconocida en la ciudad de Iruña, situada en la llanada occidental alavesa, se ha fechado en época julio-claudia, mientras que es en época flavia cuando se detecta la existencia de una densa red de asentamientos rurales. El centenar de asentamientos rurales altoimperiales conocidos en la actualidad se ubican en las llanuras y en los fondos de valle, y diseñan una estructura de hábitat dispersos y jerarquizada que pivota en torno a pocos núcleos centrales, siendo en cambio muy abundantes las pequeñas granjas y asentamientos menores. A pesar de que los especialistas han insistido en la centralidad del patrón viario a la hora de explicar esta jerarquía (GIL 1996: 29), resulta asimismo evidente que coexisten otras lógicas organizativas del espacio basados en la existencia de centros dirigentes de percepción de excedentes (con frecuencia identificados con mansiones ${ }^{4}$ ), de los que dependen $\mathrm{o}$ en torno a los cuales se articulan otras redes de asentamientos menores. Este tipo de estructura jerárquica se reconoce con mayor claridad en la llanada central alavesa, en la que se localiza la ciudad de Veleia. Es menos aprehensible, en cambio, en el sector occidental y en las zonas de montaña, donde la profundidad jerárquica está menos marcada (fig. 3).

Tras una profunda crisis del poblamiento rural y urbano, que parece que hay que situar en el siglo III d. C., se va a producir una profunda reestructuración de los asentamientos tardorromanos en el período tetrárquico (fig. 4). Por un lado se asiste a una contracción del poblamiento, de manera que se produce el abandono de más de un $40 \%$ de los asentamientos altoimperiales. Asimismo se detecta una profunda reestructuración en términos jerárquicos, de manera que los asentamientos rurales menores parecen ser los más penalizados a favor de los centros intermedios, mientras que se funda media docena de nuevos pequeños asentamientos en el sector oriental alavés. Esta transformación se puede relacionar con la tendencia a la concentración de las propiedades, y quizás del poblamiento, que se documenta en amplios sectores del imperio en época tardorromana (VERA 1986), lo que va a tener consecuencias muy notables en la reestructuración de las jerarquías creadas en el altoimperio.

A diferencia del sector meseteño no se ha documentado una monumentalización de los núcleos jerárquicos principales (Albeiurmendi, Salbatierrabide, Las Ermitas, etc.), salvo en el caso de la uilla de Cabriana (Comunión) ${ }^{5}$, que ha sido remodelada en la primera mitad del siglo IV y se ha dotado de un rico aparato decorativo. No parece casual que este asentamiento se encuentre en la periferia alavesa, a orillas del Ebro, en la cuenca de Miranda. Se trataría, por lo tanto de una de las muchas haciendas de grandes dimensiones en manos de funcionarios $y$ aristócratas que encontramos en algunos sectores peninsulares, generalmente residentes en centros urbanos (CHAVARRIA 2004: 70-74).

Por último, y por lo que se refiere a la propia ciudad de Veleia, el siglo III representa un

\footnotetext{
4 Sobre esta temática específica, véanse los importantes trabajos realizados en Mariturri (Vitoria-Gasteiz), donde se ha reconocido tanto una mansio como un vicus (NÚÑNEZ MARCÉN, SAÉNZ DE URTURI 2005).

5 I. Filloy, E. Gil (2000: 127) cuestionan que se trate de una uilla, ya que suponen que se trate de una mansio.
} 
momento de reestructuración, que dará paso a un nuevo modelo urbanístico en época tetrárquica mediante la construcción de un reciento amurallado y la reorganización de los espacios domésticos (GIL 2000: 49-5I).

Pero si el paisaje alavés se va a transformar de forma profunda durante finales del siglo III y el siglo IV, en el siglo $V$ observamos una profunda cesura, ya que se asiste a la desarticulación final de las jerarquías del poblamiento romano y al abandono masivo de asentamientos rurales. Las tres pautas principales que parecen caracterizar la conformación del paisaje alavés a partir del 400 aproximadamente son las siguientes:

I. Se produce la transformación y el abandono de numerosos asentamientos, lo que comporta el fin de las jerárquicas anteriores.

2. Se produce la ocupación de espacios "marginales" y periféricos respecto al período anterior.

3. Se crean nuevos centros jerárquicos que siguen una nueva lógica y reflejan la existencia de una estructura de poder aún radicada en el territorio.

Trataremos a continuación cada una de estas temáticas de forma más detallada.

\section{La desarticulación de las jerarquías anteriores}

Los datos de los que disponemos en la actualidad son aún parciales, puesto que salvo casos puntuales, carecemos de un número relevante de yacimientos excavados en extensión. En todo caso, durante el período comprendido entre finales del siglo IV y el siglo $V$ asistimos al abandono de los asentamientos rurales principales, mientras que el centro urbano de Iruña muestra una continuidad de ocupación hasta al menos el siglo Vl.

Por lo que se refiere a la ciudad de Iruña los datos disponibles aun son fragmentarios. No obstante, el proyecto de investigación IRUÑA-
VELEIA III. Milenioa está proporcionando nuevas informaciones de gran relevancia para analizar la evolución de este yacimiento. A la espera de una síntesis global, los datos de los que disponemos nos muestran que la transformación de la ciudad altoimperial tuvo lugar a partir del siglo III, cuando se produjo una profunda redefinición de la ciudad. Se produjo a partir de entonces la reducción del área ocupada (se pasa de 80 a II Ha), y se dotó la urbe de un recinto amurallado. Las estructuras bajoimperiales, en ocasiones realizadas sobre construcciones anteriores como en el caso de la denominada Domus de Pompeia Valentina, se amortizan en el curso del siglo $V$. Asimismo las ocupaciones que se han detectado en la excavación de la muralla, correspondientes a ocupaciones domésticas adosadas al propio recinto, enterramientos y ocupaciones extramuros, parecen igualmente amortizarse en el curso del siglo $\mathrm{V}$. Se ha reconocido del mismo modo una ocupación medieval, como encomienda de la Orden de San Juan, pero la discontinuidad es evidente respecto a las fases romanas (GIL ZUBILLAGA 2003-2005). Arqueológicamente no se conocen restos que se puedan fechar en los siglos VII y VIII, a pesar de que una de las crónicas del ciclo de Alfonso III hace referencia a Uelegia Alabense como una de las localidades que fue asolada por el rey asturiano Alfonso I.

El análisis del territorio rural muestra realidades más articuladas y complejas. Un caso paradigmático está representado por la ya mencionada uilla de Cabriana (FILLOY, GIL 2000: 102-104). En proximidad de las estructuras residenciales excavadas, que parecen perdurar hasta el siglo $V$, se ha excavado una mínima parte de una amplia necrópolis fechada entre el último cuarto del siglo IV y mediados del siglo V. Las 54 inhumaciones halladas han sido encuadradas dentro del fenómeno de las denominadas "necrópolis del Duero", caracterizadas por la presencia de ricos ajuares. En todo caso, la existencia de necrópolis que amortizan las propias estructuras de las villae o se ubican en su proximidad es un fenómeno recurrente en muchos establecimientos tardorromanos del occidente mediterráneo, que ha sido explicado tanto en términos ideológicos y simbólicos como de continuidad en la explotación del fun- 
dus más allá del abandono del sector residencial (CHAVARRIA 200 I; 2004: 82-83). En el caso de Cabriana la contemporaneidad entre la ocupación del espacio residencial y la necrópolis podría estar indicando la existencia de espacios domésticos de rustici que explotan el fundus y que se entierran en proximidad del centro de la uilla.

También en el caso de Salbatierrabide (Vitoria-Gasteiz) parece que el asentamiento, que perdura hasta mediados del siglo $V$, ha sido posteriormente ocupado por una necrópolis que se fecha hasta el siglo VII (GIL 1990). Sin embargo, se trata de excavaciones realizadas a inicios del siglo $X X$ y de las que carecemos de una documentación adecuada (UGARTECHEA 1967).

En síntesis, salvo excepciones puntuales podemos afirmar que en torno al 450 se ha producido la desarticulación de la estructura jerárquica de los asentamientos tardorromanos alaveses y el abandono de la mayor parte de los mismos. Tras esa fecha se mantienen algunos núcleos centrales, y en primer lugar Iruña, aunque progresivamente pierde su carácter urbano. Otros núcleos rurales principales se transforman radicalmente, de manera que se mantienen como centros de referencia, incluso una vez que se han abandonado sus espacios residenciales.

\section{La ocupación de espacios "marginales"}

Un fenómeno documentado cada vez con mayor frecuencia en los últimos años en Europa y en el Mediterráneo occidental es el de que en época tardorromana y altomedieval se ocupan espacios y nichos ecológicos considerados durante los siglos anteriores como absolutamente periféricos o "marginales". Se trata, en todo caso, de una marginalidad relativa, ya que este proceso debe entenderse como el resultado del desarrollo de nuevas formas de explotación económica del espacio por parte de comunidades campesinas que siguen nuevas lógicas productivas (GUTIÉRREZ LLORET 1996: 3II). Tradicionalmente la ocupación de estos espacios se ha relacionado con fenómenos de inestabilidad política o como resultado de la decadencia del paisaje agrario romano. No obstante, el hallazgo en los contextos de los siglos $\checkmark$ y VI de cerámica importada nos señalaría cómo estos asentamientos estaban inmersos en los principales circuitos comerciales.

El abandono parcial de los espacios llanos y los fondos de valle nos indicaría por un lado una cesura social y económica, que se reflejaría en los modelos de gestión de estas propiedades. A su vez, la ocupación de espacios "improductivos" por parte de pequeños grupos de campesinos -ya que hasta el momento solamente se han detectado ocupaciones de pequeñas dimensiones- mostraría una multiplicidad de situaciones y de estrategias productivas cualitativamente diferentes $y$ destinadas a tener un protagonismo sustancial desde mediados del siglo $\vee$ hasta finales del siglo VII.

Más concretamente en el territorio alavés se ha reconocido tres tendencias principales:

\section{LAS OCUPACIONES RUPESTRES}

La temática de las ocupaciones rupestres referida a los siglos tardoantiguos y altomedievales en el territorio alavés ha merecido la atención de un número importante de estudiosos; de hecho, varias de ellas han sido objeto de excavaciones a lo largo de los años (El Montico, los Goros, Corro, Marquínez, Laño, Los Husos, etc.). Se trata de una cuestión que, indudablemente, requiere de una profunda y urgente revisión y reinterpretación (p.e. BARRIOS, MARTíN VISO 2000-200 I: 75), ya que se configura como una de las piezas claves a la hora de analizar las formas de ocupación del espacio durante los siglos $\mathrm{V}$-VII en este territorio ${ }^{6}$. Como resulta obvio, no es nuestra intención realizar esta revisión en esta ocasión, ya que

6 Asimismo en otros territorios cercanos, como Guipúzcoa, se han reconocido ocupaciones tardorromanas en cuevas como Iruaxpe III, Amalda, Antón Koba, Iritegi, etc. 
excedería con mucho los objetivos que ahora nos hemos planteado.

En todo caso, y de forma extremadamente sucinta, se puede señalar cómo los trabajos más recientes han interpretado desde varios parámetros este tipo de ocupaciones. Así por ejemplo L. A. Monreal (1989), en su síntesis dedicada al alto valle del Ebro, tiende a agrupar la práctica totalidad de este tipo de cuevas en términos de "colonias semieremíticas", de iglesias o, en el caso de cuevas de mayores dimensiones, en centros para "reuniones comunitarias", siempre desde una óptica religiosa (MONREAL 1989, 31 I).

En cambio, en su tesis doctoral, A. Azkarate ha relativizado estas conclusiones para el territorio alavés en cuanto que de las 1 I 8 cuevas que analiza (fig. 5), únicamente reconoce en los grupos de Faido, Albaina y Laño una funcionalidad eclesiástica (45 cavidades) y los sitúa de forma indiscutible en el siglo VI-VII (AZKARATE 1988: 479-480). Según este autor, nos encontraríamos en presencia de una ocupación rupestre tardoantigua de carácter eremítico, aunque no hace extensibles estas conclusiones para el resto de las cavidades alavesas. Recientemente ha vuelto sobre el argumento (AZKARATE, SOLAUN 2003: 38) reafirmándose en estas conclusiones y sugiriendo que a partir del siglo VII y VIII estos centros eremíticos se habrían convertido en núcleos de atracción, de cristianización y de "desarrollo agrícola", de tal manera que se vinculan con la presencia de las aldeas de Laño y Faido documentadas en el siglo XI.

Por otro lado, excavaciones realizadas en una decena de cuevas alavesas han mostrado la existencia de distintos tipos de ocupación fechadas ya desde el período tardorromano (FILLOY, GIL 2000, p. 52-54).

Resulta indudable que las mayores dificultades que plantea la interpretación de este tipo de ocupaciones residen en la necesidad de establecer su cronología y conocer su funcionalidad. Indudablemente los epígrafes conservados en siete cavidades alavesas, que han permitido situar su ocupación en los siglos VI-VII (AZKA-
RATE 1988: 386-422), constituyen un importante punto de partida a la hora de comprender el momento ocupacional de algunas de las iglesias rupestres. Pero la ausencia de contextos de excavación limita notablemente la posibilidad de comprender en su complejidad la naturaleza de estas ocupaciones.

En todo caso, las síntesis más recientes realizadas en otros contextos europeos (p.e. RAYNAUD 200 I) coinciden en señalar que se trata de un fenómeno complejo y heterogéneo, de manera que no todos los abrigos responderían a los mismos patrones.

Sin pretender ni mucho menos agotar la temática, se pueden aportar algunos datos que contribuyan a replantear en su complejidad la problemática en Álava y su entorno.

Así por ejemplo la cueva de Iruaxpe III, situada en el macizo de Orkatzategi (Guipúzcoa), en el límite entre Álava y Guipúzcoa, se ha constatado la existencia de una ocupación tardorromana fechada en el siglo $V$ y la primera mitad del VI (AZKARATE, NUÑEZ, SOLAÚN 2003: 327-342). En este caso las excavaciones realizadas han llevado a sugerir que se trata de una ocupación estacional de carácter ganadero (LÓPEZ COLOM, GEREÑU, URTEAGA 1997: 154-156). Quizás esta misma función podría aplicarse a otros abrigos excavados en Guipúzcoa en la proximidad de la divisoria de aguas con Álava, como podría ser el caso de las cuevas de Iritegi (URIBARRI 1994) o Antón Koba (ARMENDÁRIZ 1985-1993).

En cambio, en otros abrigos se ha podido documentar la existencia de una ocupación estable de carácter doméstico, como el caso de Kobairada, Solacueva de Lacozmonte, Peña Parda o los abrigos de Los Husos (FILLOY, GIL 2000, 53). En estos últimos, enclavados en la Sierra de Cantabria, las excavaciones recientes realizadas por J. Fernández Eraso han permitido recuperar elementos significativos para establecer la naturaleza y la cronología de su ocupación. Más concretamente en Los Husos II se ha reconocido la existencia de una ocupación doméstica caracterizada como cabaña o choza (FERNÁNDEZ ERASO 2006: 62), en la que se han 
hallado algunas cerámicas fechables en los siglos V-mediados del VI. Más concretamente se trata de formas 37 de TSHT y de un bol de DSP (lám I), que podría fecharse entre el siglo $\vee y$ el primer cuarto del siglo VI (FERNÁNDEZ ERASO 2005: 66). No obstante, las dataciones radiocarbonicas realizadas a partir de carbones hallados en estos niveles de ocupación han permitido fechar en los siglos III-VII el uso de este abrigo.

También en Los Husos I se ha podido documentar una ocupación fechada radiocarbónicamente en los siglos III-VI así como residuos de carácter doméstico (fauna, vidrio, cerámica tardorromana) que nos muestran la naturaleza de la misma (FERNÁNDEZ ERASO 1999: 46).

Se han fechado, en cambio, con cronologías más avanzadas otro conjunto de cavidades y abrigos en los que se reconocen otras funcionalidades diferentes, tanto de carácter funerario como religioso.

Entre ellas se pueden situar el caso de Los Goros (PALOL 1970), abrigo situado en la llanada occidental alavesa, y en la que se ha documentado la existencia de dos sepulturas con ajuares fechables en los siglos VI y VII. Asimismo en el conjunto de la Cueva de los Moros (Corro), situado en el occidente alavés, se han realizado hace algunos años unas excavaciones en el exterior del abrigo denominado los Moros II (SÁENZ DE URTURI 1990). En estos sondeos se reconoció la existencia de un cementerio en el exterior de la cueva, recuperándose un total de cinco esqueletos. La datación radiocarbónica de uno de éstos, una vez calibrada, permite situar en el curso de los siglos VII-VIII el deceso del individuo. Se puede plantear como hipótesis que se trate de un centro eclesiástico vinculado a una posible aldea cercana, más que como un centro de carácter eremítico.

En el caso de los conjuntos de treviñeses de Faido, Albaina y Laño (lám 2), para los que se ha propuesto una cronología entre los siglos VI-VII (AZKARATE 1988: 480), podría sugerirse una funcionalidad similar a la de los Moros, excluyendo su carácter eremítico y relacionándolos con las pautas de ocupación social de los espacios "marginales" a los que venimos haciendo referencia.

\section{LA OCUPACION DE ALTURAS}

Otro fenómeno que se documenta con cierta frecuencia en amplios sectores europeos durante el período tardoantiguo y altomedieval es la ocupación de zonas de altura (perchement), tratándose con frecuencia de reocupaciones de asentamientos prerromanos.

En el caso alavés solamente se han reconocido, hasta el momento, ocupaciones de esta naturaleza en un sector muy concreto del territorio, el suroeste, aunque es probable que se trate de un fenómeno que haya tenido un mayor desarrollo. Más concretamente dos son los asentamientos en los que se han reconocido ocupaciones tardorromanas de pequeña entidad.

En el caso del castillo de Ocio (Zambrana), las prospecciones y las recientes excavaciones realizadas con ocasión de la restauración del conjunto han mostrado la existencia de una larga secuencia ocupacional que se extiende entre el Hierro I, la época romana y Alta Edad Media. No obstante, la entidad de los sondeos realizados no ha permitido caracterizar de forma adecuada más que las fases de ocupación altomedievales. Se puede fechar con anterioridad al año mil una torre cuadrada exenta, dotada probablemente de un aljibe y de un recinto amurallado, y posteriormente integrada en la estructura castellana actual (SOLAÚN, SÁNCHEZ 2003: 218). Los materiales tardorromanos se han hallado en prospecciones, pero no ha sido posible reconocer o establecer con precisión la naturaleza de la ocupación de este período.

El segundo ejemplo es el del castillo de Portilla (lám 3), situado en proximidad del anterior en las estribaciones del monte Txulato, a 750 m. de altura (FERNÁNDEZ BORDEGARAY 19921995). Se trata de un yacimiento igualmente ocupado desde el Hierro I, que cuenta con una ocupación tardorromana y que al parecer vuelve a ocuparse a partir de la fase final de la Alta Edad Media. Las excavaciones realizadas en las terrazas situadas al sur del castillo han permitido reconocer la existencia de un asentamiento 
tardorromano de carácter doméstico en el que se han hallado dos pequeños hogares, un molino de mano circular, algunos metales y TSHT (FERNÁNDEZ BORDEGARY 1995: 102).

A la hora de explicar este tipo de yacimientos tradicionalmente se ha recurrido como criterio básico a la inestabilidad del período aunque, como hemos señalado, es posible que tengamos que ubicar su naturaleza en el marco de las transformaciones socioeconómicas que caracterizan este momento. En todo caso, y a la espera de la edición final de las intervenciones en estos yacimientos, parece que nos encontramos en presencia de ocupaciones tardorromanas breves y que no perduran en la Alta Edad Media.

\section{LOS ESPACIOS GANADEROS}

Investigaciones recientes sobre la evolución paleoclimática realizadas en Cataluña, la Meseta, los Pirineos, el sur de la Galia o los Apeninos italianos han mostrado como la Alta Edad Media se caracteriza por una profunda transformación paisajística y de los espacios productivos. Estas transformaciones se habrían producido como resultado de la interacción entre los cambios paleoambientales y la acción antrópica con lógicas productivas radicalmente diferentes a las documentadas en el período romano y a las que se impondrán en época medieval. Sin pretender ser exhaustivos se puede señalar cómo los datos arqueobotánicos, arqueozoológicos y arqueológicos indican que durante los siglos V-VIII se han producido una importante degradación hidroclimática de las llanuras del sureste francés (BERGER 200I: 379-384) que favorecieron el desarrollo de humedales y de espacios ganaderos. En Cataluña se ha detectado en el entorno de Barcelona la existencia de una extensa deforestación que favoreció una intensa erosión y la formación de prados húmedos aprovechados para el desarrollo de una actividad ganadera trashumante a partir del siglo VI-VII (PALET, RIERA 1994). Esta actividad trashumante se detecta en el Rosellón y los Pirineos catalanes, donde son evidentes las transformaciones del paisaje como resultado de la actividad ganadera (GALOP 1998: 82-83). Este fenómeno se ha reconocido asi- mismo en las alturas de Prato Spilla (Parma, Italia), donde se ha podido documentar cómo durante los siglos VI-VII el bosque extensivo de época romana ha sido sustituido por un nuevo sistema de prados con pastos arbolados resultado de la deforestación y la producción de heno (DAVITE, MORENO 1996). En el Apenino toscano se ha documentado a partir de los siglos V-VI la existencia de una profunda transformación de los espacios forestales mediante la sustitución del bosque mixto mediterráneo por extensiones de pastos arbolados en los que el castañedo de fruto se ha convertido en la especie dominante (QUIRÓS CASTILLO 1998). Igualmente en Salamanca los datos arqueobotánicos muestran el desarrollo a partir del siglo $\mathrm{V}$ de una atención preferente a la ganadería y una mayor presión sobre el bosque. En cambio a partir del siglo VIII se observa una menor presión sobre el medio forestal que ha sido interpretada como un retroceso de la actividad ganadera y el desarrollo de una importante actividad cerealícola (ARIÑO GIL, RIERA MORA, RODRÍGUEZ HERNÁNDEZ 2002: 296-302).

Aunque las cronologías y los procesos presentan variantes muy significativas en cada territorio europeo, resulta indudable que en época altomedieval las lógicas productivas que habían caracterizado el mundo romano van a ser sustituidas por un nuevo modelo económico, menos especializado y dependiente de la exportación. Nichos ecológicos y productivos que hasta el momento habían tenido un papel secundario o periférico van a adquirir un renovado protagonismo, y actividades como la ganadería comercial basada en la trashumancia a larga distancia documentada en época romana va a ser sustituida por una ganadería de ámbito local que sigue lógicas productivas propias de pequeñas comunidades rurales.

En el País Vasco aún no contamos con datos paleoclimáticos y arqueobotánicos suficientemente significativos para los siglos V-X. Los análisis paleobotánicos realizados en la turbera de Saldropo (Vizcaya) o en la ferrería de Oiola (Trapagaran, Vizcaya) muestran una importante deforestación en torno al año mil, pero carecemos de datos para los siglos anteriores. No obstante, es importante señalar que se han 
documentado en varios cordales del País Vasco la existencia de ocupaciones de carácter pastoril que han sido fechadas mediante el empleo de dataciones radiocarbónicas en época romana, pero sobre todo altomedieval, que han permitido constatar la existencia de una reactivación de la explotación ganadera durante la Alta Edad Media.

Un primer conjunto de ocupaciones se han reconocido en la sierra de Urbía (GuipúzcoaÁlava), dominando la llanada alavesa oriental. En las prospecciones realizadas en los años 80 en este entorno se han reconocido una serie de estructuras de carácter ganadero fechadas en los siglos altomedievales. Más concretamente dos construcciones sondeadas en el lugar denominado Kalparmuño se han fechado entre los siglos IV-VII y entre los siglos IX-XII (URTEAGA, UGALDE, GANDIAGA 1992-1993: 79).

Igualmente en Guipúzcoa se han realizado recientemente varias prospecciones en la Sierra de Aralar (MORAZA BAREA, MÚJICA ALUSTIZA 2006) que han permitido documentar varios "fondos de chabola tumulares". Un total de diecinueve de estas estructuras han sido sondeadas y fechadas mediante el análisis radiocarbónico de sedimentos, lo que ha permitido ubicar cronológicamente su ocupación entre los siglos VI y XVII. Es cierto que se observa una mayor concentración de dataciones entre finales del siglo IX y finales del siglo XIII, cuando es posible que se produjera una ulterior potenciación de la ganadería trashumante a corta distancia en relación con el desarrollo de la red aldeana, de los mercados y las ciudades. Por otro lado los autores apuntan cómo en esta sierra se ha desarrollado en estos siglos una ganadería vacuna, tal y como han mostrado los datos arqueozoológicos recogidos en los sondeos, de tal manera que la introducción de los ovinos sería muy reciente.

Por último es importante subrayar que este tipo de ocupaciones de altura han sido reconocidas en la comarca pirenaica de la Cerdaña, donde las excavaciones de construcciones y espacios ganaderos han mostrado igualmente la reactivación de los espacios de montaña en la Alta Edad Media (RENDU 2003: 430 ss).
En síntesis, aunque los datos de los que disponemos sobre los espacios de montaña del País Vasco son aún parciales, permiten pensar que el desmantelamiento del sistema productivo romano favoreció la ocupación de espacios productivos marginales de monte y de bosque en los que se desarrolla un nuevo modelo económico de carácter silvo-pastoril.

Resulta evidente, por tanto, que será preciso realizar en los próximos años excavaciones en extensión en estas estructuras para conocer la naturaleza de las ocupaciones, así como disponer de registros botánicos que permitan comprender las formas de ocupación y explotación de estos paisajes.

\section{La jerarquía del poblamiento en los siglos VI-VII}

Este es seguramente uno de las temáticas más complejas de identificar en el estado actual de nuestros conocimientos, no solamente en Álava, sino en general en toda la Península lbérica durante los siglos V-VIII. Mientras las síntesis más recientes de los historiadores tienden a señalar la existencia de fuertes poderes territoriales radicados en la península ibérica durante los siglos V y VII (ARCE 2005; CASTELLANOS, MARTÍN VISO 2005; WICKHAM 2005), el registro material encuentra grandes dificultades a la hora de reconocer tanto los asentamientos de estos poderosos, como los efectos y las formas en que ejercieron este poder.

Varios autores han señalado el papel central que habrían jugado los castella tardoantiguos como centros de poder y de articulación territorial, aún reconociendo la variabilidad de estos asentamientos (ESCALONA 2002, CHAVARRIA 2005: 267-269). Aparentemente estos castra habrían tenido un papel relevante en la estructura fiscal del reino visigodo, o bien habrían constituido las cabeceras de nuevas jerarquías del poblamiento alternativas a los modelos anteriores (CASTELLANOS, MARTíN VISO 2005).

Estas fortificaciones parecen ser más frecuentes en aquellos espacios en los que escasean las ciudades o donde su capacidad de articular el territorio es menor. $Y$ no debemos 
olvidar que en la Meseta aproximadamente un $70 \%$ de las ciudades parece que se han abandonado o perdido su carácter urbano hacia el 550 (QUIRÓS CASTILLO, BENGOETXEA 2006).

En el territorio alavés contamos con un único yacimiento que se puede identificar con un castellum, el castro de Buradón, a pesar de que se ha excavado únicamente una porción del mismo y de que ocupa una posición periférica dentro del territorio alavés.

El castro de Buradón se ubica en las Conchas de Haro, un estrecho desfiladero atravesado por el río Ebro en el límite de La Rioja y Álava. Se trata de un risco calizo presidido por una torre, en cuya ladera sur, caracterizada por una fuerte pendiente, se han hallado materiales y restos arqueológicos pertenecientes a varios períodos históricos. El castillo de Buradón está documentado al menos desde el año 964 como una de las tenencias de los condes castellanos, de tal manera que constituirá un centro de poder relevante en el espacio alavés, al menos bajo el dominio castellano.

Las prospecciones realizadas en el yacimiento han permitido reconocer la existencia de una ocupación protohistórica y medieval, aunque no fue hasta los años 90 cuando se realizaron las excavaciones de la ladera meridional con ocasión de la realización de un túnel en el desfiladero. En esta excavación, que recuperó nuevos restos protohistóricos, se pudo detectar la existencia de una ocupación ininterrumpida fechada entre el siglo IV y la plena edad media (UNZUETA, MARTINEZ 1994).

A partir del siglo IV el yacimiento fue reocupado mediante el acondicionamiento de la ladera sur con un sistema de terrazas escalonadas sobre las que se dispusieron una serie de estructuras de carácter doméstico de las que se han excavado nueve viviendas, y la realización de una iglesia en su sector inferior.

La primera fase de la iglesia de Buradón presenta una planta rectangular orientada al Sureste, con unas dimensiones interiores de
I7 $\times 5$ m y con cabecera tripartita. En la nave se ha hallado una piscina bautismal cuadrada, y el edificio ha sido realizado con paramentos de mampostería reforzados en las esquinas revestidos con estucos pintados.

Mientras que las viviendas se han fechado en los siglos IV-VI, la iglesia se ha atribuido al siglo $\mathrm{V}$. En cambio, la necrópolis asociada a la iglesia, formada por enterramientos realizados en fosa simple, se ha fechado por dataciones radiocarbónicas en los siglos VI-VII.

Sobre esta necrópolis se ha documentado la reconstrucción y ampliación del templo tardoantiguo mediante el añadido de un ábside de herradura (fig. 6) que rompe el testero tripartito anterior. La iglesia se orienta al Este, presenta una nave de unos $12 \mathrm{~m}$, y tiene un presbiterio que sobresale de la planta. La cubierta del ábside debió ser realizada con cúpula de piedra, si atendemos a la cantidad de toba recogida en el derrumbe interior. Su cronología, determinada por criterios morfológicos y estilísticos, se ha establecido en el siglo $X$.

Asociada a esta iglesia se ha excavado una necrópolis formada por más de 200 enterramientos de lajas, que denotan la existencia de una comunidad campesina que no ha podido ser identificada. Los niveles de destrucción de la iglesia y del conjunto permiten pensar que fue en el siglo XII cuando se abandonó definitivamente el yacimiento.

Se trata, por lo tanto, de un yacimiento complejo y difícil de interpretar con los datos con los que contamos actualmente. La presencia o ausencia de un recinto amurallado o la propia organización urbanística del asentamiento tras el siglo VI son aún desconocidas. Sin embargo, es el único yacimiento alavés en el que aparentemente se puede constar la existencia de una continuidad ocupacional entre los siglos IV y XII. Asimismo el urbanismo compacto que se observa en las fases de los siglos IV-VI (UNZUETA, SALCEDO 1994: 54), recuerda el de otros asentamientos fortificados coetáneos como el de Bernardos (Segovia) o el de Puig Rom (Gerona). 
En todo caso el paralelo más cercano está representado por el conjunto del Vallejo de Santillán (Traspaderne, Burgos), excavado hace unos años a los pies del castro tardoantiguo y altomedieval de Tedeja (LECANDA 2000: 197199). También en este caso se ha hallado un centro de culto asociado a varios enterramientos y otras construcciones que se han fechado entre el período tardorromano y altomedieval.

Por lo tanto podríamos considerar la iglesia de Buradón, no tanto como la expresión de élites locales, sino como una iglesia vinculada a un asentamiento concentrado que constituye un centro de poder territorial de carácter subregional, quizás alternativo o complementario a la propia ciudad de Iruña. La presencia de iglesias asociadas a estos castra, promovidos por el propio estado, se ha documentado asimismo en otros sectores europeOS (BROGIOLO, CHAVARRIA 2005: I40-|14|; WICKHAM 2005: 479). Nuestro desconocimiento más detallado del asentamiento en los siglos VII$I X$ no permite reconocer hasta qué punto se mantiene como centro jerárquico superior en el momento en que se produce la formación del paisaje medieval articulado en aldeas. En todo caso, al menos desde el siglo $X$, y dentro del marco de las estructuras de poder castellanas, Buradón se presenta como un centro de poder principal en el suroeste alavés.

En síntesis, aunque la interpretación global del asentamiento sigue planteando algunos problemas, los elementos con los que contamos sugieren que estamos en presencia de un castellum tardoantiguo y altomedieval, cuyo significado en términos de centros de poder territorial ha sido evidenciado por las investigaciones realizadas en Galia, Italia y otros sectores peninsulares (BROGIOLO, CHAVARRIA 2005: 69 ss).

\section{Reflexión final}

Como ha señalado recientemente C. Wickham (2005: 493-494), si se pretende reconocer en el registro arqueológico altomedieval la existencia de diferenciaciones sociales, el análisis de la complejidad de los intercambios y la articulación de las jerarquías de poblamiento constituyen dos guías muy importantes. Por lo que se refiere al primer criterio, la existencia de grupos sociales lo suficientemente ricos como para poder generar una demanda que sustente una producción de calidad o su inexistencia en un contexto socialmente más homogéneo, se podría reconocer en el registro material. En cambio, la presencia de una estructura jerárquica del poblamiento reflejaría el peso de los grandes propietarios.

Los estudios más recientes realizados sobre la circulación de la cerámica en el País Vasco han mostrado cómo es entre finales del siglo $\mathrm{V}$ y el siglo $\mathrm{VI}$ cuando se pueden documentar las últimas importaciones de cerámica de mesa, consistente esencialmente en DSP. Para el territorio alavés, contextos como los de Los Husos son bastante significativos de estas últimas fases. A partir de mediados del siglo VI los datos de los que disponemos nos muestran la existencia de producciones cerámicas realizadas con tecnologías elementales en ámbitos domésticos, lo que sugiere la carencia de una demanda socialmente diferenciada (AZKARATE, NÚÑEZ, SOLAUN 2003). lgualmente en las necrópolis de los siglos VI-VII dotadas de ajuares metálicos y vítreos, que han dado pie a sugerir la existencia de poderes locales fuertes que coyunturalmente se apoyarían en poderes centrales (GARCÍA CAMINO 2002: 328), se han hallado formas cerámicas realizadas con tecnologías elementales. Sin querer entrar ahora en los problemas interpretativos de estas necrópolis ${ }^{7}$,

\footnotetext{
7 Temática, por otro lado, compleja y espinosa. Entre las síntesis más recientes hay que señalar los trabajos de AZKARATE 2004, que parece reconocer en estas necrópolis un proceso de "etnogénesis" y de formación de una "identidad franca", cuyos planteamientos han sido cuestionados por autores como COLLINS 2005, pp. 191-193, que en cambio reconoce en estas necrópolis poblaciones militarizadas, sin otorgarles connotaciones étnicas. Como se ha señalado, I. GARCÍA CAMINO (2002) apuesta en cambio por una lectura en términos de poderes territoriales en el contexto de la frontera. Asimismo han propuesto distintas interpretaciones autores como A. Besga, A. Iriarte Kortazar, H. W. Böhme, etc. Hay que señalar que los análisis antropológicos realizados en algunas necrópolis peninsulares (Goges, Castiltierra), han mostrado que se trata de necrópolis de campesinos, mientras que en la
} 
no parece que estos datos arqueológicos deban ser leídos necesariamente en términos de poderes fuertes en el País Vasco durante estos siglos, al menos a nivel supralocal, y probablemente solo el reconocimiento y la excavación de los poblados de los vivos y de sus espacios productivos permitirá interpretar desde nuevas bases los propios poblados de los muertos.

Por lo que se refiere, en cambio, a la estructuración social que se puede detectar en la jerarquía poblacional, con los datos actualmente disponibles se puede afirmar que el territorio alavés conoce tras el 450 la quiebra del paisaje antiguo que habría dado paso a una multiplicidad de soluciones y de realidades -que en parte aún se nos escapan- caracterizados por la ocupación de espacios "marginales" y por la creación de centros de poder alternativos.

Como hemos visto con anterioridad, el siglo $\checkmark$ constituye un punto sin retorno en la dimensión urbana de Veleia. Es cierto que el asentamiento perdura aún hasta el siglo VI, pero aparentemente pierde su dimensión urbana. Asimismo los asentamientos principales tipo uillae languidecen en el curso del siglo V. Frente a la quiebra de estos sistemas, el castellum de Buradón parece indicarnos la creación de un nuevo orden jerárquico alternativo, que denota la presencia de élites que siguen teniendo una capacidad de ordenación del territorio, aunque su efectividad es menor que en el período anterior (WICKHAM 2005: 255-258). No parece posible, por lo tanto, hablar en Álava de paisajes desestructurados o "caóticos" durante los siglos V-VII (VALENTI 2004: 65-77), a pesar de que se haya producido un reequilibrio de las jerarquías poblacionales.

Por otro lado, las investigaciones realizadas en los últimos años han mostrado como la ocupación de zonas "marginales" o periféricas, constituye una de las características más signi- ficativas de los nuevos asentamientos ocupados en la Alta Edad Media. Espacios ocupados de forma marginal dentro del contexto social y económico vigente durante la época romana cobran ahora un nuevo protagonismo en una coyuntura económica y social diversa. No se debe olvidar, en todo caso, que en las cuevas $y$ en los yacimientos de altura con ocupaciones fechadas en el siglo $\mathrm{V}$ o inicios del siglo $\mathrm{VI}$ es posible encontrar materiales cerámicos importados y de calidad semejantes a los hallados en otros asentamientos coetáneos. Resulta, por lo tanto, improbable pensar que nos encontramos en presencia de ocupaciones esporádicas, socialmente marginales o relacionadas con situaciones de inestabilidad política. Estos asentamientos participan de circuitos comerciales complejos, y por lo tanto la razón básica que puede explicar este tipo de ocupación se relaciona únicamente con la decisión voluntaria de los residentes de desplazarse a un nuevo nicho ecológico más favorable al desarrollo de actividades productivas diferentes a las que se desempeñaban en las llanura y en los fondos de valle donde se ubican la gran mayoría de los asentamientos alto y medio imperiales.

En todo caso, lo que resulta indudable es que el paisaje alavés en torno al 500 era muy diferente al romano, de tal manera que la fractura de las jerarquías de asentamientos constituye un indicador precioso de las transformaciones que han tenido lugar a nivel social.

Son muchos los puntos oscuros que quedan por resolver, especialmente en lo que se refiere a las formas de ocupación y explotación del espacio durante los siglos VI y VII antes de que se formasen las nuevas aldeas medievales. Las investigaciones de los próximos años deberían incidir en la comprensión del siglo comprendido entre el 550-650, que actualmente se presenta como una fase muy compleja.

\footnotetext{
Meseta cada vez aparece con mayor claridad su asociación con las aldeas campesinas. En este contexto resulta sugestivo pensar en que los diferentes rituales y la riqueza de los ajuares reflejaría diferencias sociales internas en el seno de los mismos asentamientos campesinos, más que élites y poderes sopralocales. ¿Puede aplicarse esta idea a las necrópolis alavesas? (QUIROS CASTILLO, VIGIL ESCALERA, 2006)
} 


\section{LAS ALDEAS DE LOS ARQUEOLOGOS: EL CASO DE ÁLAVA}

En los últimos diez años distintas intervenciones arqueológicas realizadas esencialmente como fruto de actuaciones preventivas o "de gestión" han permitido recuperar los restos de casi dos decenas de aldeas altomedievales en Álava que presentan distintos grados de conservación (fig. 7). A pesar de que únicamente siete de estos yacimientos han podido ser fechados, estamos en condiciones de defender que es en torno al 750 cuando se ha creado una red de aldeas y un paisaje que ha perdurado prácticamente hasta nuestros días. La cesura que ha supuesto la creación de estas aldeas en términos de historia social nos permite situar en este momento el inicio de la Edad Media en Álava.

Es cierto que la entidad material de estas aldeas complica notablemente el reconocimiento de sus restos y el estudio de los mismos. Se trata de asentamientos caracterizados por una cultura material muy poco sofisticada, formada por estructuras domésticas de tierra, madera, barro y, en ocasiones, zócalos de piedra; silos excavados directamente en la roca; pocas cerámicas, puesto que se empleaban formas de madera, etc. Esta "invisibilidad" del registro ha causado que, hasta hace pocos años, las intervenciones arqueológicas realizadas en los despoblados y aldeas alavesas medievales no hayan permitido reconocer más que necrópolis y ermitas.

Ello ha provocado que el registro con el que contamos sea parcial, de difícil ordenación y en buena parte inédito, por lo que en esta ocasión solo se pretende realizar una sistematización de las aldeas excavadas y proponer una primera lectura de las mismas. Asimismo, hay que señalar que contamos con excavaciones realizadas en extensiones muy limitadas ${ }^{8}$, lo que dificulta ulteriormente su interpretación. En todo caso, se ha aplicado un cuestionario de investigación similar al que se está desarrollando en otros contextos europeos (en particular, FRANCOVICH, HODGES 2003), lo que nos permite reconocer las analogías y las diferencias que presenta el territorio alavés respecto a otros espacios.

Hasta el momento se han excavado un mayor número de yacimientos en la Llanada, en la Rioja Alavesa y en la cuenca de Miranda, por lo que hay sectores alaveses aún descubiertos. Por este motivo se intuye la existencia de diferencias subregionales, aunque aún es pronto para poder establecer una geografía de las aldeas alavesas.

En esta ocasión, nos limitaremos a analizar tres aspectos principales; la estructura de estas aldeas; sus cronologías y la estructura social de las mismas.

\section{La estructura de las aldeas}

Las aldeas alavesas altomedievales que han sido excavadas hasta el momento se suelen ubicar, salvo casos puntuales, en espacios fértiles de fondo de valle, en colinas y en espacios llanos, donde se encuentran la red de aldeas aún en la actualidad. Incluso en aquellos casos en los que las aldeas ocupan pequeñas lomas o colinas (Gasteiz, Zornoztegi, Alto de Santo Domingo, Mavilla, etc.), dominan amplios espacios llanos. Únicamente en el sector occidental alavés, donde se localizan asentamientos como Los Castros de Lastra, las aldeas se disponen en altas colinas que dominan amplias porciones de valle. Frente a las ocupaciones "marginales" que han caracterizado los siglos anteriores, nos encontramos pues, frente a un nuevo patrón de ocupación y de explotación del territorio, reflejo de una nueva estructura social.

\footnotetext{
8 Así por ejemplo, 160 m² en Las Sepulturas; 140 m² en Estavillo; 98 m² en Zornoztegi. El mayor yacimiento excavado en extensión hasta el momento es el de Gasteiz, en el que se han realizado varias intervenciones en los últimos años que han sacado a la luz evidencias de la aldea altomedieval. Sin duda la intervención más importante hasta el momento es la que se está realizando en la Catedral de Santa María (AZKARATE, SOLAUN 2003), donde se han excavado varios miles de metros cuadrados.
} 
En términos materiales, la arquitectura doméstica de estas aldeas se caracteriza por una cultura material muy poco sofisticada, al estar constituida por construcciones de madera, tierra y piedra, no siempre fáciles de detectar y de difícil conservación. Al momento actual los únicos yacimientos en los que se han hallado construcciones domésticas atribuibles a este período son los de Zornoztegi, Gasteiz, Reinavilla, Las Sepulturas, Eskide, Legardagutxi, Los Castros de Lastra y quizás el de Valparaíso de Valdegobía.

\section{LOS SILOS}

Indudablemente el registro material que presenta una mayor visibilidad y que ha sido reconocido con mayor frecuencia son los numerosos silos destinados al almacenaje de cereales, de manera que en Álava se han excavado y hallado más de 150 de cronología altomedieval (fig. 9) 9 . A diferencia de otros restos materiales más frágiles, como las huellas de poste, construcciones de tierra o edificios poco consistentes, resulta evidente que los silos excavados en las arcillas o en la roca natural son bien reconocibles, especialmente cuando quedan expuestos en sección debido a obras recientes. De hecho, en muy pocos casos ha sido posible excavar contemporáneamente los silos y las estructuras domésticas a las que están asociadas, por lo que no se ha podido realizar un análisis contextual de este tipo de estructuras. Son frecuentes, en cambio, los casos en los que únicamente se han excavado conjuntos de silos, a veces en número muy reducido (Landatxo, Ansoleta, Armiñón, La Llana, etc.). Algunos autores piensan, incluso, que los campos de silos estarían aislados respecto a los espacios residenciales o en los espacios de producción, aunque los datos de los que disponemos excluyen esta posibilidad (CENICEROS, CLAVIJO 1993, p. 73; GIL 2004, p. 290).
A la hora de analizar este tipo de estructuras hay que evitar identificar de forma mecánica el hallazgo de silos y la existencia de aldeas altomedievales. Este sistema de almacenamiento constituye un recurso utilizado con gran frecuencia en Álava en varios ámbitos territoriales y cronológicos (p.e. BALDEÓN, SÁNCHEZ SIERRA 2003). Sin embargo, los trabajos más recientes han mostrado igualmente que el recurso a silos de notable capacidad, aparentemente mayores respecto a los de la Edad del Bronce y del Hierro alaveses, constituye una de las características más marcadas de las aldeas de los siglos VIII-XI.

Otro aspecto que plantea el análisis de este tipo de estructuras es que a través de su excavación no se puede analizar, fechar e interpretar el momento de su construcción, sino el abandono y la reutilización del silo como basurero de actividades domésticas (lám 4). Y aunque es cierto que estos silos se rellenan con los deshechos domésticos de las viviendas cercanas, y por lo tanto podemos reconocer de forma indirecta la naturaleza de la ocupación, es prioritario lograr excavar la asociación entre las viviendas, los espacios domésticos y las áreas de almacenaje.

Entre los deshechos más abundantes que aparecen en el interior de estos silos hay que señalar la presencia de materiales constructivos, de objetos muebles y de restos de comida. Entre los primeros suelen ser frecuentes la presencia de pequeñas piedras o mampuestos, que generalmente se disponen en el fondo de los silos, que podrían indicarnos la presencia de zócalos o de pequeñas construcciones realizadas en piedra. Estos mampuestos han aparecido en el relleno de silos fechados en el siglo VIII (Zornoztegi, Estavillo, La Llana), por lo que hemos de pensar que ya en los primeros compases de estas aldeas se contaría con arquitecturas realizadas en técnicas mixtas. Asimismo se

\footnotetext{
9 Se trata de un cálculo por defecto, y es probable que su número se deba situar en torno a los dos centenares. La presencia de silos como indicadores de aldeas altomedievales no es fenómeno exclusivo de Álava, sino que se detecta en numerosos territorios castellanos, como por ejemplo en Monzón de Campos, Palencia (DE LA CRUZ, LAMALFA 1994), o navarros (JUSUÉ I988: 304305). Ver asimismo FERNÁNDEZ UGALDE 1997.
} 
han hallado maderas carbonizadas, manteados o revocos de adobe (Las Sepulturas, Zornoztegui) $y$, en el caso de rellenos plenomedievales, también tejas (p.e. en Vitoria-Gasteiz, Salinillas de Buradón).

Suelen ser asimismo muy abundantes los hallazgos de materiales muebles, entre los que destacan la cerámica rota que se ha arrojado a estos basureros. Sin entrar ahora a analizar estos materiales, hay que señalar que en el relleno de varios silos se han recuperado materiales de época romana o incluso prerromana (Landatxo, La Llana, Vitoria-Gasteiz, Mavilla, etc.). La presencia de estos materiales residuales nos muestra la existencia en proximidad de estas aldeas de asentamientos más antiguos cuyos materiales se habrían incorporados residualmente a la basura que finalmente acaba en el relleno del silo como resultado de la limpieza de la superficie circundante al área residencial.

De forma más esporádica se hallan en estos rellenos materiales metálicos de carácter doméstico o constructivo (carpintería de armar) y algunos vidrios.

Representan una constante en la excavación de los rellenos de los silos el hallazgo de restos de fauna. Aunque aún no han sido estudiados de forma unitaria y completa estos materiales, constituyen en el momento actual el mejor registro arqueofaunístico disponible para comprender aspectos básicos de la estructura económica de estas aldeas.

Hasta el momento no parece que se hayan recogido cereales residuales en el interior de los silos, como ha ocurrido en otros yacimientos (DE LA CRUZ, LAMALFA 1994: 605), aunque sería necesario flotar los sedimentos siguiendo una estrategia global de análisis de este tipo de contextos cerrados.

Por lo que se refiere a la capacidad de los silos hay que señalar que, aquellos que no han sido alterados por las tareas agrícolas posteriores y en los que la medición ha sido posible, pueden agruparse en dos categorías principales. Un primer grupo de silos de pequeñas dimensiones (lám. 5) que cuenta con capacidades de
2- 12 Hl, podrían estar destinados al almacenaje de la simiente para la próxima siembra. El segundo grupo (lám. 6) está formado por silos de gran capacidad de almacenaje de cereales (20-40 HI) o incluso de capacidad muy grande $(50-60 \mathrm{HI})$. Las fuentes históricas indican que para alimentar anualmente una familia de 8- 10 personas son necesarios unos $32 \mathrm{HI}$ de cereal aproximadamente (FERNÁNDEZ UGALDE 1993: 615), por lo que este segundo grupo parece corresponder al almacenaje tipo de un grupo familiar. Por otro lado hay que tener en cuenta que los silos han de mantener un ambiente anaeróbico en su interior (GAST, SIGAUT 197I), lo que condicionaba su utilización y los sistemas de cierre y mantenimiento del cereal. En el curso de estudios etnoarqueológicos realizadas en Marruecos se ha podido observar que lo silos se abrían cada cierto tiempo (3-4 semanas) de manera que germinaba la capa superior de cereales que era desechada (PEÑA et alii 2000: 4II).

Para concluir hay que señalar que con frecuencia los silos están muy cercanos entre sí, aunque raramente llegan a superponerse en los despoblados y en los asentamientos rurales, debido a que se carece de una estratigrafía horizontal compleja. Solamente en las aldeas que han perdurado hasta nuestros días se detecta esta complejidad, o en casos particulares, como Mavilla. Esta multiplicación de los silos nos indica que probablemente ha sido frecuente la renovación de este tipo de estructuras de almacenaje y su sustitución por otras fosas similares.

\section{LAS ESTRUCTURAS DOMÉSTICAS}

Por lo que se refiere a las estructuras domésticas, ya hemos señalado que contamos con un muestreo aún muy reducido como para poder realizar una caracterización adecuada de estas construcciones. Por eso, en esta ocasión, solamente se mencionarán algunos de los contextos más significativos.

El yacimiento más destacado es el de la aldea de Gasteiz, donde se ha reconocido la existencia de una longhouse asociada a varios fondos de cabaña y espacios abiertos delimi- 
tados por una zanja, definiendo un modelo de ocupación del espacio ampliamente documentado en otros contextos europeos (AZKARATE, SOLAUN 2003). Se ha atribuido a los siglos VIIIIIX una primera fase, en el que las construcciones se realizan únicamente con madera, tanto a nivel de suelo como semienterrado, con un entramado urdido revestido por arcilla y cubierta vegetal (AZKARATE, QUIRÓS 200I). En un segundo momento, atribuido al siglo $X$, se observa el empleo de zócalos de piedra y alzados de tierra. Igualmente en la Plaza de Santa María se han hallado construcciones domésticas realizadas en adobe (GIL ZUBILLAGA 1998).

Asimismo el empleo de construcciones realizadas en tierra se ha reconocido en la aldea de Zornoztegi, aunque aún no se han excavado en extensión. En Los Castros de Lastra, en cambio, las estructuras domésticas atribuidas a los siglos $I X$ y $X$ han sido realizadas en piedra, mientras que en Valparaíso de Valdegobía, una aldea atribuida a la Alta Edad Media pero que no cuenta con indicadores cronológicos precisos, se ha reconocido una serie de orificios y agujeros de poste destinados al alojamiento de una cubierta (SÁENZ DE URTURI 1982-1998; ALONSO, CASTELLET, FERNÁNDEZ 1992-1993: 159). También en Las Sepulturas (San Vicente de la Sonsierra), se ha hallado el ángulo de una estructura de carácter doméstico realizado con mampuestos aparejados a seco (GIL ZUBILLAGA 200 I: 97), aunque tampoco en este caso ha podido ser fechado con precisión.

En síntesis, los datos disponibles son aún muy parcos, por lo que será necesario en los próximos años realizar nuevas excavaciones en extensión que permitan estudiar contextos domésticos, así como reconocer las culturas constructivas presentes en Álava en la Alta Edad Media ${ }^{10}$. Es cierto que se empiezan a detectar diferencias territoriales y cronológicas en las técnicas de construcción y en las tipologías edilicias, pero deberemos evitar simplificaciones excesivas a la hora de interpretar en términos sociales los distintos ciclos de producción y la estructura del artesanado.

\section{EL MODELO URBANISTICO}

Teniendo en cuenta las extensiones excavadas, es muy prematuro trazar una primera propuesta de organización urbanística de estas aldeas. Las futuras intervenciones deberán abordar este problema, aunque resulta evidente que se ha producido una transformación profunda entre las "aldeas agregadas" altomedievales y las "aldeas compactas" actuales.

No se puede olvidar, a este propósito que la lectura realizada desde las fuentes escritas en casos paradigmáticos como el de Alcedo en el siglo X ha llevado a J. A. García de Cortazar a definir un modelo de compactación y articulación del caserío altomedieval muy diferente respecto al actual. Tomando como ejemplo una de las aldeas alavesas mejor conocidas documentalmente, Alcedo (Lantarón), este autor ha establecido una comparación entre la morfología compacta que presenta en la actualidad respecto al urbanismo que debería presentar en la segunda mitad del siglo X (fig. 8, lám. 7), y que este autor describe como una agregación de pequeñas unidades domésticas autónomas separadas con eras, próximas a una ermita (GARCÍA DE CORTAZAR 1981, p. I52) '!. Igualmente E. Pastor ha propuesto recientemente un modelo aldeano poco compacto en la llanada alavesa aún para el siglo XI (PASTOR 2006).

Aunque no es demasiado fácil reconocer arqueológicamente las transformaciones urbanísticas y sociales que conlleva el tránsito entre ambos modelos de aldeas, los indicadores con los que contamos si parecen confirmar en casi todos los casos una evolución similar a la des-

\footnotetext{
10 Igualmente la documentación escrita altomedieval nos proporciona algunas indicaciones importantes sobre la naturaleza de las construcciones domésticas de este período (p.e. RUIZ DE LOIZAGA 1995, p. 103-104).

I I Para el caso navarro se puede consultar LARREA 1998, p. 504-507.
} 
crita en el caso de Alcedo, aunque con dos diferencias sustanciales; en primer lugar las unidades domésticas y productivas individuales que se sugieren para el caso de Alcedo están probablemente más separadas físicamente; en segundo lugar, el modelo que refleja la documentación en el siglo $X$ se ha gestado ya en el siglo VIII.

Nuevamente en el caso de Gasteiz, si bien el urbanismo altomedieval se caracteriza por la existencia de amplios espacios abiertos y por la presencia de unidades productivas individuales, en torno al siglo $X \mid$ se produce una profunda reordenación del espacio aldeano mediante la replanificación y lotificación de algunos sectores construidos en relación con la construcción de un recinto amurallado (AZKARATE, SOLAUN 2003).

En Zornoztegi se ha podido asimismo documentar que el asentamiento altomedieval cubre una amplia extensión articulándose en torno a viviendas y campos de silos, y en un segundo momento se produce la reordenación y agrupación del caserío en torno a la iglesia de Santa María.

Otro caso de gran interés es la aldea de Estavillo (lám. 8). Está documentada desde el año 87I, cuando una serie de señores donan al monasterio de San Vicente de Acosta las iglesias de Santa Gracia y San Martín in villa Stabellu, de illo Fresnu usque Salone, incluyendo numerosos bienes (UBIETO 194, n. 10, p. 20-2I). La iglesia de San Martín sigue siendo, aún en la actualidad, el eje en torno al cual se organiza de forma compacta el pueblo de Estavillo, mientras que Santa Engracia es una de las ermitas que han desaparecido (LÓPEZ DE GEREÑU 1962: 525). Asimismo el documento recoge una microtoponimia que denota la existencia de una clara estructuración interna de la aldea. Hace casi diez años, con ocasión de la construcción de unas viviendas en finca Mavilla situada a unos $200 \mathrm{~m}$ de las últimas viviendas de Estavillo, se excavaron un total de diecisiete silos que habían sido parcialmente amortizados por la construcción de una ermita dedicada a San Sebastián (APELLANIZ, AJAMIL 1998). Cronológicamente los silos se pueden fechar en la
Alta Edad Media, mientras que su amortización tuvo lugar en el siglo $X-X I I$, cuando se construyó la ermita mencionada. Podríamos, a través de este ejemplo, reconocer nuevamente la existencia de un modelo aldeano laxo y agregado en la Alta Edad Media, como el de Alcedo, mientras que en torno al año mil se habría producido un proceso de compactación y concentración de las unidades domésticas en torno a una sola iglesia, convertida en esta ocasión en centro parroquial.

Para otros centros aún habitados, como Rivabellosa y Nanclares de la Oca, los datos son más limitados, aunque no se contradicen con el modelo trazado. Por lo que se refiere al primer caso, se han realizado varias intervenciones en torno a la primitiva iglesia de San Martín, transformada en casa consistorial tras el desplazamiento del centro parroquial. En los solares cercanos se han hallado varios conjuntos de silos, conservados en algún caso únicamente en sección, lo que permiten pensar en la existencia de una densa ocupación altomedieval sobre la que posteriormente se construirá la iglesia (APELLANIZ GONZÁLEZ 200 I; AJAMIL BAÑOS 2003, 2005). También en este caso se puede intuir que fue en el siglo XI cuando se produce una verdadera renovación del urbanismo aldeano. En la redacción del Fuero de Miranda de Ebro, fechado en el año I099, se describen las villas e iglesias que dependen de Miranda, y entre ellas se menciona "in rippa uellosa quatuordecim solares iuxta ecclesiam sancti martini: sex sub calle superiori et octo inter callem de medio et callem inferiorem et medietatem ecclesie" (CANTERA Y BURGOS 1998: 64).

Probablemente sea similar el pueblo de Nanclares de la Oca, puesto que en proximidad de la iglesia de la Asunción se excavaron un conjunto de nueve silos con ocasión de la realización de varias viviendas (LLANOS 1987, n. 6009, p. 345; GIL 1999). Sin embargo los datos son muy parciales.

Se diferencia del modelo urbanístico propuesto el despoblado de Reinavilla (Laguardia), que ha sido estudiado por L. Gil (GIL ZUBILLAGA 1997). De este despoblado proviene un epígrafe, quizás de carácter funerario, fechado 
en el año 762 (ELORZA 1970: 283-284), aunque no se ha podido establecer hasta el momento la existencia de una necrópolis o de un centro de culto coetáneo al mismo. Los sondeos realizados en el altozano han reconocido la existencia de una primera fase de ocupación en la ladera suroeste atribuida a la Alta Edad Media que se correspondería con un pequeño asentamiento de 0,3 Ha. En un segundo momento, posterior al año mil, el asentamiento se habría expandido hacia el norte, donde se construyó la ermita del poblado y una necrópolis que se ha mantenido en uso hasta el siglo XIV.

En todo caso parece que el proceso de "compactación" (GARCÍA DE CORTAZAR 1985: 83) debe situarse en torno a los siglos XI y XII, cuando las numerosas iglesias altomedievales se convierten en parroquias en torno a las cuales se agrupa el caserío.

\section{LA ESTRUCTURA ECONOMICA DE LAS ALDEAS}

Aunque resulta claro que los elementos disponibles son aún parciales, podemos afirmar sin ninguna duda que la aparición de estas aldeas supone una profunda cesura en la morfología de los paisajes altomedievales alaveses.

Es cierto que nuestro conocimiento sobre las estrategias de producción que caracterizan los asentamientos campesinos precedentes a las aldeas es muy parcial, aunque parecen indicar modelos productivos poco especializados, en el que la explotación de espacios "marginales" y ganaderos adquiere un notable protagonismo. En cambio, en yacimientos como el castillo de Buradón se detecta la existencia de una estructura más especializada.

Como acabamos de ver, uno de los indicadores más significativos de las aldeas altomedievales alavesas es la presencia de numerosos silos, la mayor parte de los cuales cuenta con una capacidad de 20-40 HI, lo que permitiría almacenar de forma aproximada la producción cerealícola correspondiente a 10-20 Ha (GIL 2004: 290). Resulta indudable, pues, que nos encontramos en presencia de una producción agrícola extensiva especializada, que no obs- tante se va a integrar con una importante actividad ganadera, tal y como aparece en las ocupaciones de altura reconocidas en las Sierras de Urbía y Aralar, o en la documentación escrita. La integración entre ambos sectores productivos, que implica necesariamente un grado de coordinación y ordenación social de los espacios productivos en el seno de las aldeas así como la existencia de territorios aldeanos (FERNÁNDEZ MIER 1999), es por lo tanto una práctica que se puede documentar a partir de los siglos VIII y IX en el territorio alavés.

Quedan aún por conocer aspectos básicos sobre los cultivos, las estrategias productivas y las formas de gestión y producción de excedentes. En el caso de los análisis arqueobotánicos realizados en la aldea de Gasteiz se ha podido reconocer el predominio de trigo común, cebada vestida y el panizo, cereal de primavera de consumo en el seno de las propias aldeas puesto que nunca aparece en la documentación como pago realizado a los propietarios de la tierra (AZKARATE, ZAPATA 2006).

Otro aspecto importante que caracteriza la estructura económica de las aldeas es la ordenación, ubicación y la naturaleza de la estructura artesanal que se va a gestar en el seno de estas aldeas. ¿Hasta qué punto es posible detectar la presencia de polos productivos especializados, y cómo hemos de interpretarlos socialmente? ¿Hay que relacionarlos con una demanda sostenida por parte de grupos pudientes o reflejan un sistema de intercambios complejos entre las distintas aldeas? (ver p.e. HAMEROW 2002: 156 ss.).

A través de la documentación altomedieval del monasterio de San Millán de la Cogolla (La Rioja) sabemos que las escasas estructuras artesanales documentadas en Álava se encontraban ubicadas en contextos rurales, aunque no es posible reconocer un patrón jerárquico definido. Así, en el año 87l se menciona una vía de los Olleros, y también desde el siglo IX se conoce la presencia en el territorio rural de varios herreros. Pero será a partir del siglo XI cuando se documenta la existencia de polos productivos especializados organizados por parte del propio monasterio en su entorno más inme- 
diato. En particular en el pueblo de Santurde, contiguo al monasterio, se sitúan en torno al año mil tejeros $y$, en la primera mitad del siglo $\mathrm{XI}$ torneros, molineros, pellejeros, herreros $y$ también olleros (GARCÍA DE CORTAZAR 1969).

Los principales indicadores arqueológicos disponibles para el estudio de las estructuras artesanales son, por un lado el estudio de las pautas de producción, circulación y consumo de los materiales arqueológicos; el análisis de las arquitecturas, y el reconocimiento de los centros de producción. Mientras que sobre la cerámica altomedieval alavesa es inminente la publicación de una investigación reciente (SOLAUN en prensa), y sobre la arquitectura aún contamos con datos parciales, sí se han podido reconocer en casos puntuales centros artesanales.

Los estudios cerámicos nos muestran como, a partir del siglo XI, los modelos de producción doméstica van a ser sustituidos por polos productivos más especializados, que generan mercados de ámbito microregional (AZKARATE, NÚÑEZ, SOLAÚN 2003: 367-368). Esta transformación refleja la consolidación de una jerarquía aldeana, así como de diferencias de carácter social que se plasman en la creación de una demanda más articulada y ordenada en torno a sistemas comerciales. De hecho, es precisamente a partir del siglo XI cuando se generen las pautas de jerarquización social de la red aldeana que preanuncia el desarrollo posterior de las villas (QUIRÓS, BENGOETXEA 2006).

En el caso de la aldea de Gasteiz contamos con indicadores concretos que muestran la existencia de una estructura artesanal más desarrollada. Aunque no se han podido fechar en términos absolutos las estructuras halladas en el sector de excavación 3 de las manzanas de casas I y IV del Casco Histórico (FERNÁNDEZ BORDEGARAY 1998: 225), el tipo de evidencias arqueológicas permite relacionarlas con las ocupaciones domésticas altomedievales halladas bajo la cercana Catedral de Santa María (AZKARATE, SOLAUN 2003). Agujeros de poste, pozos, hogares, silos, etc. orientan hacia una ocupación cronológicamente similar en el Campillo. En el mencionado sector de excavación se ha hallado un horno de fundición metalúrgico que, aunque no cuenta con una datación absoluta, constituye el primer indicio arqueológico del que disponemos en la actualidad sobre la importante actividad metalúrgica que sugieren las fuentes que se desarrollaba en Álava en torno al año mil (GARCÍA DE CORTAZAR 1978). Otro indicio que permitiría pensar en una datación temprana de esta estructura sería la propia presencia de estructuras artesanales en el interior de una aldea que se ha ido densificando, y que desde el siglo XI cuenta con un recinto amurallado. A este propósito hay que señalar que es precisamente a partir de este período cuando se documenta en otras ciudades la segregación de los sectores artesanales más peligrosos y contaminantes, así como su polarización en los suburbios.

\section{Las cronologías de las aldeas}

Uno de los problemas más complejos que plantea en la actualidad el estudio de estas aldeas está representado por la necesidad de contar con una serie de dataciones precisas que permitan ubicar el momento en que se produjo su formación. De hecho, varios autores han reflexionado sobre la complejidad que plantea atribuir una datación precisa a los contextos domésticos altomedievales, puesto que se trata -no lo olvidemos- de un registro complejo y difícil de sistematizar.

La documentación escrita, que ha sido hasta el momento el instrumento principal que se ha utilizado para fechar, muestra la existencia únicamente de pocas decenas de aldeas, núcleos, villae, ecclesia, monasteria en el período altomedieval. Solamente tras el año mil esta documentación nos indica la presencia de una densa red de aldeas en el territorio alavés. Un importante documento del año 1025 redactado por los monjes del monasterio de San Millán de la Cogolla (La Rioja) y conocido con el nombre de "Reja de San Millán", recoge la lista de 307 pueblos que estaban obligados a pagar al mencionado monasterio "rejas" de hierro (293 pueblos) y cabezas de ganado ( 14 pueblos). Curiosamente la autenticidad de este documento ha sido cuestionada, no tanto por criterios paleográficos o documentales, cuanto por el hecho 
de que no resultaba fácilmente asumible que en esta fecha pudiesen existir tantas aldeas y una actividad metalúrgica tan desarrollada (ver la crítica de GARCÍA DE CORTAZAR 1981: |43).

Volviendo al registro material, únicamente en siete aldeas excavadas contamos con dataciones arqueológicas precisas, aunque su número se puede ampliar si consideramos otros indicadores, como la cerámica hallada en los rellenos de los silos reutilizados como basureros. No obstante, en este último caso contamos con un margen de precisión amplio, debido a las propias características de la producción cerámica de la Alta Edad Media en Álava (AZKARATE, NÚÑEZ, SOLAUN 2003). Una parte sustancial de estas cerámicas han sido producidas en el seno de pequeñas comunidades campesinas con un alto grado de autosuficiencia. Son cerámicas realizadas con sistemas de cocción poco sofisticados, con un repertorio formal reducido y poco estandardizado en ausencia de mercados estructurados.

Para cuatro yacimientos contamos con dataciones radiocarbónicas (La Llana, Gasteiz, Zornoztegi, Mavilla). Mientras que los primeros tres yacimientos permiten situar en el siglo VIII la formación de las aldeas, en el último caso el relleno de los silos se ha podido situar entre los siglos X-XIl.

Por otro lado la aldea de Reinavilla podría igualmente situarse en el curso del siglo VIII debido al hallazgo de una lápida fechada en el año 762. Es cierto que desconocemos el contexto arqueológico del que proviene, pero esta cronología es coherente con los materiales arqueológicos hallados (GIL ZUBILLAGA 1997).

El cambio, el yacimiento de Los Castros de Lastra se puede fechar en el siglo IX a partir de los materiales arqueológicos y las estructuras identificadas (SÁENZ DE URTURI 1982-1998).

Por último hay que señalar que la iglesia de San Martín en Rivabellosa, fechada en el siglo XI constituye un término ante quem para fechar las ocupaciones domésticas anteriores. No obstante, nuevos análisis radiocarbónicos deberán perfilar y precisar estas dataciones.

\section{Iglesias y poderes locales}

Aunque el número de excavaciones y la naturaleza de las mismas no permiten más que sugerir algunas interpretaciones, los datos de los que vamos disponiendo llevan a pensar que en el seno de las propias aldeas es posible detectar a partir del siglo $X$ la presencia de poderes locales. Con anterioridad, las arquitecturas domésticas reconocidas no permiten, hasta el momento, detectar diferenciaciones sociales netas entre los habitantes de las aldeas. Tampoco otros indicadores materiales, como el registro faunístico, arqueobotánico o cerámico, permiten intuir este tipo de diferencias. En todo caso hay que tener en cuenta que únicamente cuando contemos con un registro arqueológico de mayor calidad, en términos extensivos y cualitativos, podremos reconocer con mayor precisión la configuración social de estas aldeas en sus fases iniciales (p.e. HAMEROW 2002: 9-1I).

Uno de los indicadores más significativos de este tipo de procesos está representado por la construcción de iglesias en el interior de las propias aldeas. En el cercano territorio vizcaíno I. García Camino se preguntaba recientemente si la iglesia precedía a las aldeas y mediatizaba su génesis, o si en cambio las iglesias nacían dentro de las aldeas. Este autor apostaba por la última posibilidad (GARCÍA CAMINO 2002: 336).

Los datos con los que contamos para el territorio alavés nos muestran que el proceso de fundación de iglesias rurales está constatado al menos desde el siglo VIII, especialmente en el sector occidental, que cuenta con una importante documentación escrita. No obstante no sabemos aún si las primeras iglesias o monasteria, como por ejemplo San Román de Tobillas (AZKARATE, FERNÁNDEZ DE JÁUREGUI, NÚÑ̃EZ 1995: 7I-74), están vinculadas a núcleos aldeanos o están topográficamente aisladas.

Hay que tener en cuenta que se trata de un tema complejo y que precisaría de nuevas excavaciones y estudios. La documentación escrita recoge la existencia de un mayor núme- 
ro de iglesias que de aldeas en los siglos IX y $X$ (PEÑA BOCOS 1995: 127). Es cierto que son sobre todo las iglesias los objetos de las donaciones y cesiones que aparecen en los documentos, pero también es cierto que son muy frecuentes los casos de aldeas documentadas a partir del siglo XI que cuentan con varias iglesias.

Sin embargo se trata de una temática de difícil estudio debido a que son muy pocos los conjuntos arquitectónicos altomedievales que se han conservado en alzado hasta nuestros días. Un reciente estudio sistemático del patrimonio eclesiástico alavés ha mostrado que únicamente se conservan 24 edificios que pueden ser fechados antes del año mil cien (SÁNCHEZ ZUFIARRE, en prensa). En cambio son muy abundantes las noticias de ermitas desaparecidas y de topónimos, de tal manera que en los más de 500 pueblos y localidades alavesas actuales contamos con noticias de más de dos mil iglesias, ermitas desaparecidas o hagiotopónimos (LÓPEZ DE GEREÑU 1962: 517-537). Resulta evidente que no todas las iglesias se han fundado en la Alta Edad Media, y de hecho son muy frecuentes las fundaciones de ermitas en época moderna. Pero por otro lado sabemos que en los últimos siglos de la Alta Edad Media ha sido muy numerosa la edificación de iglesias propias por parte de determinadas élites.

En términos globales los datos arqueológicos con los que contamos nos muestran que, salvo el caso de la iglesia de Los Castros de Lastra, fechada en el siglo IX, y considerada como coetánea a la formación de la aldea altomedieval (SÁENZ DE URTURI 1982-1998), el resto de los templos analizados se habrían construido en el seno de las aldeas siglos después de su creación. Este es un fenómeno que con frecuencia se está constatando en otros contextos europeos, como en el caso italiano, en el que las iglesias no han jugado un papel relevante en la formación de las aldeas y en la creación de identidades locales (FRANCOVICH 2004: XVII).

Asimismo se ha observado que la fundación de estas iglesias en el interior de las aldeas pro- dujo una profunda reordenación urbanística, y con frecuencia supuso la amortización de espacios domésticos. Este fenómeno se puede documentar en Mavilla, Rivabellosa o Gasteiz.

En esta última aldea la excavación de la iglesia hallada en la Catedral de Santa María ha mostrado que su realización tuvo lugar en el curso del siglo XI-XII, adosándose a un recinto amurallado y amortizando espacios de uso doméstico (AZKARATE, SOLAÚN 2003).

Igualmente la construcción en el siglo XI de la iglesia de San Martín de Rivabellosa supuso la amortización de silos y áreas domésticas altomedievales (AJAMIL 2005). También en Mavilla (Estavillo) ya se ha señalado que la ermita de San Sebastián comportó el abandono del campo de silos allí excavado (APELLANIZ, AJAMIL 1998).

En otros casos en los que carecemos de excavaciones en extensión se ha podido observar cómo lo silos se han hallado en proximidad de iglesias y sus cementerios. Esto ocurre en los dos tercios de las aldeas excavadas, teniendo en cuenta que en el tercio restante aún no ha sido identificado el templo que con frecuencia está documentado (p.e. Landatxo, Nanclares de Oca, Las Sepulturas, etc.).

Teniendo en cuenta estos datos podemos pensar que es al menos desde los siglos $X-X \mid$ cuando se hace patente la presencia de nuevos poderes en el interior de las aldeas. Aún no tenemos criterios para saber cómo inciden estos poderes en la reorientación de las estrategias productivas, en la captura de excedentes (BARCELÓ 1995) y si son poderes que se gestan desde dentro de las aldeas o desde el exterior de las mismas.

Resulta evidente que el espacio aldeano va a sufrir una profunda modificación y una nueva ordenación, de tal manera que las iglesias articulan con nuevos criterios el urbanismo anterior. Aparentemente aún durante el siglo $X I$ e incluso el Xll observamos cómo en las aldeas pueden pervivir varias iglesias, aunque probablemente varias de ellas se hayan fundado siglos antes. Solamente en un tercer momento, ya a 
partir del siglo XII, es cuando una de estas iglesias termina adquiriendo un carácter parroquial, degradando al papel de simples ermitas otras fundaciones propias (QUIRÓS CASTILLO 2003).

Asimismo, en el caso de Gasteiz resulta muy significativo señalar que el mismo espacio doméstico podría estar marcando la existencia de un patrón de apropiación y fijación del espacio que podría ser interpretado en términos de diferenciación social. Nos referimos en particular a la longhouse identificada en el curso de las excavaciones de la catedral de Santa María, y fechada en el siglo IX (AZKARATE, QUIRÓS CASTILLO 200I: 34-39; AZKARATE, SOLAUN 2003). Su permanente reconstrucción durante los siglos en el marco de un urbanismo cambiante nos muestra la existencia de un proceso de apropiación y fijación de determinados espacios residenciales. Por otro lado, las investigaciones más recientes han permitido reconocer el significado de las longhouse precisamente a partir del $800 \mathrm{ca}$. como centros diferenciados de poder en el seno de las aldeas europeas (HAMEROW 2002: I4-26; VALENTI 2004: 100 ss.), aunque será preciso definir con precisión estos indicadores del poder.

No debemos olvidar, no obstante, que la construcción de iglesias, la apropiación estable de espacios residenciales o la construcción de grandes construcciones no nos permitirán observar más que de forma refleja las jerarquías sociales. Solamente cuando contemos con registros arqueológicos adecuados podremos explicar las transformaciones de las producciones campesinas, las formas de apropiación de los excedentes (BARCELÓ 1995) y las formas de construcción de los poderes locales.

Para concluir hay que señalar que nuestro muestreo es aún parcial y no permite más que evienciar la existencia de varios tipos de poderes que inciden en la formación y la articulación de las aldeas en los siglos VIII-X. Mientras los historiadores señalan la existencia de "dos álavas", una más estratificada a partir del siglo $X$ al oeste del río Bayas y otra menos jerarquizada socialmente al este del mismo río (GARCÍA DE CORTAZAR 1983: 87), la arqueología de las aldeas es capaz de evidenciar la pre- sencia de estos poderes a través de la lectura de las iglesias únicamente en el sector este. Esta aparente paradoja ha de obligarnos a reflexionar sobre la parcialidad de los registros que manejamos y la dificultad que supone establecer generalizaciones en una fase aún inicial de construcción del documento arqueológico.

\section{CONCLUSIONES}

Como se ha señalado al inicio, en esta ocasión se ha querido exclusivamente realizar una primera sistematización de una serie de intervenciones arqueológicas que proporcionan importantes informaciones para repensar la Alta Edad Media alavesa. Muchas son las temáticas que solamente se han sugerido o que plantean problemas tales que harán necesario volver sobre ellas.

Para concluir este texto se ha creído oportuno abordar únicamente dos cuestiones; la supuesta continuidad existente en algunos yacimientos alaveses entre el período antiguo y medieval, y proponer algunas ideas básicas para explicar por qué es en el siglo VIII cuando se forman las aldeas.

\section{La continuidad entre el período antiguo $y$ el medieval}

Como se ha defendido en este texto, el siglo VIII representa una verdadera cesura en la historia del mundo rural alavés. Siguiendo a otros arqueólogos, podríamos plantear que es en este momento cuando se inicia la Edad Media y se agota un período y un modelo social que se había gestado en el curso de los siglos V-VII. A partir del siglo VIII vemos como los espacios "marginales" y periféricos se abandonan o se transforman y se crean nuevos marcos de sociabilidad aldeana que, con notables cambios, han llegado hasta nuestros días.

No obstante, hay que señalar que algunos arqueólogos han señalado la existencia de una continuidad entre las ocupaciones romanas y medievales en el territorio alavés. Se trata de un fenómeno que se ha detectado con una 
cierta frecuencia en otros espacios peninsulares y europeos en los que se ha observado una presunta continuidad espacial de ocupación entre los yacimientos romanos y medievales.

Sin pretender abordar en toda su complejidad este fenómeno, en el caso alavés se ha reconocido la existencia de materiales de época romana y de numerosas lápidas reutilizadas en las iglesias medievales en varios despoblados y aldeas $^{12}$.

Así por ejemplo E. García Retes (1987: 485) no duda en indicar que las aldeas medievales de Aistra y de Amamio se asentaron en lugares ya ocupados en época romana, debido a la abundante presencia de materiales arqueológicos romanos hallados, o a la utilización de lápidas romanas en la iglesia de Aistra.

En el caso del valle de Urraul Bajo, en Navarra, C. Jusue ha constatado la presencia de materiales protohistóricos y romanos en cuatro de las seis aldeas medievales que ha excavado (Apardués, Ascoz, Muru y Puyo). Prudentemente esta autora sugiere que a la luz de estos hallazgos habría que pensar que en proximidad de las aldeas medievales ha existido algún tipo de pequeño asentamiento de época romana, sin proponer la existencia de una continuidad de forma explicita. No obstante, la existencia de materiales antiguos en cuatro de seis aldeas lleva a esta estudiosa a firmar que "el último asentamiento, es decir, el correspondiente a la Edad Media, corresponde a un esquema de organización del territorio anterior a dicha época" (JUSUE 1988: 289-291).

Desde nuestro punto de vista es absolutamente necesario diferenciar la continuidad de ocupación espacial de la continuidad social y de las formas de explotación del territorio. De hecho, hay que señalar que en ningún yacimiento excavado en la actualidad en todo el territorio alavés se ha podido demostrar la existencia de esta continuidad ocupacional (salvo quizás el castellum de Buradón). Así por ejemplo, la existencia de un hiato ocupacional se constata en lugares como Arkaia, donde el poblado medieval y actual se implanta sobre el yacimiento romano, o en centros como Los Castros de Lastra, Henayo o Berbeia, caracterizados por una importante ocupación prerromana y medieval.

En ocasiones contamos con indicios que podrían sugerir una cierta continuidad ocupacional, pero son difíciles de interpretar en ausencia de excavaciones sistemáticas. Solo por plantear algunos ejemplos conocidos a través de prospecciones y hallazgos casuales en la llanada alavesa se podría citar el caso de Ozabal, situado entre Guereñu y Alaiza. Se trata de un yacimiento complejo en el que se ha documentado una ocupación romana y tardorromana, en el que se ha hallado un ajuar funerario atribuido a una tumba fechada en los siglos VI-VII, y sobre el que se instala la aldea de Aba, despoblado situado en proximidad del de Luzkando, donde se han hallado numerosas lápidas romanas (IRIARTE 1991; AZKARATE 2004).

Otro ejemplo problemático estaría representado por el complejo de Henayo (AlegriaDulantzi). Se trata de un yacimiento de altura que cuenta con una importante ocupación en la Edad del Hierro (LLANOS et alii 1975) en el que ha sido hallada una lápida romana y en cuya proximidad se ubicó la aldea de Henayo con la iglesia de San Miguel de Henayo (lám. 9). A los pies de este asentamiento se encuentra Angostina, otro importante asentamiento de época romana y que podría constituir un enlace intermedio entre las dos fases de ocupación (LLANOS et alii 1975).

Estos casos podrían multiplicarse, pero no permitirían plantear la existencia de una continuidad ocupacional.

12 De hecho, dos tercios de todas las lápidas romanas alavesas se han hallado en ermitas e iglesias medievales. Actualmente esta temática está siendo objeto de una investigación específica por parte de E. Alfaro. 
Hay que tener en cuenta que los asentamientos romanos son yacimientos que generan un gran volumen de residuos que son fácilmente detectables y reconocibles, que se identifican con frecuencia en asentamientos posteriores. Tal como hemos dicho, en casi la mitad de las aldeas excavadas se han hallado cerámicas romanas en el relleno de silos o de viviendas. Desde nuestro punto de vista, la presencia de este "ruido de fondo", resultado del movimiento de tierras y de escombros, dejan entrever una realidad quizás más articulada del poblamiento romano menor de la que se ha supuesto hasta el momento. Es posible que haya existido un amplio número de pequeños asentamientos rurales dispersos romanos que hayan proporcionado parcialmente los sedimentos y los rellenos necesarios para amortizar algunos silos.

\section{¿Por qué se crean las aldeas?}

El estudio de la génesis de la red aldeana medieval ha constituido uno de los principales objetivos de las investigaciones realizadas por los historiadores que en los últimos años han estudiado las sociedades altomedievales. Concretamente en la Península Ibérica han sido varios los autores que han relacionado de forma necesaria e inevitable -bajo la influencia de autores franceses fundamentalmente- la formación de las aldeas con el denominado "crecimiento agrario altomedieval".

Durante los años 80 la historiografía francesa llevó a cabo una profunda revisión en términos cronológicos del proceso de crecimiento que habría caracterizado la sociedad medieval. Frente a las formulaciones que sostenían la existencia de un crecimiento agrario en el período comprendido entre los siglos XI-XIII, se planteó que este crecimiento se habría producido con anterioridad, ya en la Alta Edad Media, como se detectaba en varios análisis territoriales (Flaran 10). Este crecimiento habría implicado un desarrollo económico como consecuencia del aumento de la superficie cultivada y como consecuencia del empleo de nuevas técnicas agrarias. De forma casi unánime, los historiadores asocian la formación de las aldeas medievales a este proceso de crecimiento agrario (LARREA 1994: 163 ss, PASTOR 1996: 76 ss; MARTíN VISO 2000: 138). Incluso algunos arqueólogos han hecho suya esta propuesta (GARCÍA CAMINO 2002: 335; AZKARATE, SOLAÚN 2003: 39; ARIÑO et alii 2004), validando de esta manera propuestas realizadas desde una documentación escrita escasa, parcial y poco representativa.

Sin agotar el tema, creo que son tres las principales observaciones que se pueden hacer a esta propuesta interpretativa por lo que se refiere al Norte peninsular:

I. En primer lugar, la existencia de un crecimiento agrario altomedieval se basa en una minusvaloración de la economía agraria precedente. Así por ejemplo se ha caracterizado la estructura agraria de época visigoda en términos de "predominio del bosque, del espacio no humanizado y de cultivos itinerantes" (PASTOR 1996: 92), que habría dado paso en cambio a una economía agrícola a partir del siglo VIII, y se sigue defendiendo la existencia de asentamientos fluctuantes y efímeros (AZKARATE 2004: 39). La arqueología de las aldeas medievales (VIGIL ESCALERA 2006), hasta hace poco marginalizada y olvidada por su carácter no monumental, cuestiona abiertamente este modelo y plantea la existencia de una estructura económica mucho más compleja y articulada (VIGIL ESCALERA 2003). De hecho, resulta muy difícil establecer en términos cuantitativos si la producción agraria de la Meseta de los siglos $\mathrm{VI}-\mathrm{VII}$ es inferior a la de los siglos VIII-X ${ }^{13}$. Indudablemente se produce una transformación en términos cualitativos, aun-

\footnotetext{
13 "De nuevo, poco o nada parece variar en la situación campesina desde la caída del Imperio hasta la fundación de los nuevos centros de poder islámicos entre los siglos $\mid X$ y $X$ d. C., embriones de villas que cambiarán por vez primera la configuración del territorio medieval madrileño" (VIGIL ESCALERA 2003: 65).
} 
que no tiene por qué representar un cambio radical en términos cuantitativos.

2. En segundo lugar, los trabajos que argumentan la existencia de un crecimiento agrario altomedieval tienden a describir más que a explicar este crecimiento. De hecho, es un proceso que parece no tener sujeto histórico (BARRIOS, MARTÍN VISO 2000-200I: 76 ss.).

Solamente en algunos textos se intuye que este crecimiento ha debido de ser espontáneo y realizado por los propios campesinos presionados por el hambre (Salrach) o bien siguiendo una estrategia opuesta a la de la aristocracia, que se ha orientado hacia la ganadería (Pastor). Como ha sostenido $\mathrm{M}$. Barceló (1994: 131), resulta evidente que "la hipótesis del hambre es perfectamente contradictoria con el aumento demográfico, ¿Cómo va a crecer una población hambrienta en els limits de la pura subsistencia?'.

3. En tercer lugar, un análisis riguroso de la documentación escrita realizado por $M$. Barceló ha llevado a concluir que difícilmente es posible sostener la existencia de un crecimiento agrario generalizado como resultado de roturaciones. En el caso catalán, que cuenta con una rica documentación altomedieval, se ha podido constatar que las menciones documentales son parciales y dispersas geográficamente, de manera que se concentran en torno al centro emisor de documentos (BARCELÓ 1994: 133). Para el caso alavés son aún más problemáticas, puesto que hasta el siglo Xl, cuando el documento conocido como la Reja de San Millán recoge la existencia de un amplísimo número de aldeas, la documentación es muy parcial, a pesar de que se ha sostenido igualmente la existencia de una importante serie de roturaciones durante los siglos $|X-X|$ (PASTOR 1988: 515).

¿Se puede proponer otro modelo explicativo diferente al denominado "crecimiento agrario altomedieval"? ¿Es posible cuestionar este modelo, construido a partir de un registro documental parcial y problemático, surgido por la necesidad de explicar la "revolución del año mil" en términos de acaparación de forma brusca de excedentes que se habrían generado con anterioridad de forma espontánea, sin la participación de poderes? ¿Las roturaciones y presuras equivalen a crecimiento? ¿Es necesario recurrir a la existencia de un "crecimiento agrario" para explicar la creación del paisaje medieval? ¿Con el registro arqueológico disponible, podemos proponer otra solución?. No pretendemos en estas notas abordar este complejo problema, aunque si se quieren aportar algunas sugerencias para el debate.

Los datos con los que contamos sobre los asentamientos anteriores no permiten sostener la existencia de un modelo económico "empobrecido", aunque si parece que sigue lógicas productivas diferentes. Por lo tanto no se trataría de una transformación de carácter cuantitativo sino cualitativo, y utilizar categorías actuales como "crecimiento" puede ser confuso. Desde nuestro punto de vista es más relevante explicar y analizar qué transformaciones de las estrategias y de las orientaciones productivas se han producido en este período, así como periodizar y reconocer los ciclos de transformación de la actividad agraria en los siglos VIII-X, algo que solamente la Arqueología podrá revelar en los próximos años.

En todo caso, los datos con los que contamos para analizar los procesos de configuración de los paisajes medievales alaveses permiten realizar una propuesta que deberá ser discutida en los próximos años.

En primer lugar las excavaciones arqueológicas nos muestran que el proceso de formación de las aldeas se desarrolla con total claridad ya en el siglo VIII, y por lo tanto de forma previa a la aparición documental de las mismas a partir de los siglos $|X-X|$. A priori no debemos excluir que se puedan hallar en los próximos años aldeas más tempranas, como se observa en otros contextos europeos (WICKHAM 2005: 5 I 6 ss.) o peninsulares (VIGIL ESCALERA 2006), pero con los datos actualmente disponibles parece indudable que el siglo VIII constituye un momento clave en la configuración de los paisajes medievales. 
En segundo lugar resulta indudable que el paisaje que se construye en torno al 750 aproximadamente es cualitativamente diferente respecto al de los siglos anteriores, creando nuevos marcos de sociabilidad aldeana en cuyo seno se gesta una red de relaciones sociales y de formas de poder que caracterizan la Edad Media. Son, por otro lado, aldeas que aparentemente cuentan ya desde su formación con una estructura económica compleja y diversificada, basada en la integración agrícola y ganadera, resultado de una transformación cualitativamente significativa respecto a los marcos de poblamiento anteriores.

En tercer lugar es necesario comprender quién promueve este cambio en la organización social del espacio. Esto es más difícil de contestar, y está generando un debate muy significativo a nivel europeo. Solo por referirnos al caso italiano, mientras que autores como $\mathrm{M}$. Valenti sostienen que "le origini del popolamento accentrato altomedievale sono spesso da riconoscere nella scelta spontanea delle famiglie rurali di vivere raccolte oppure, forse nella decisione di un proprietario" (VALENTI 2004: 88), G. P. Brogiolo en cambio ha subrayado el papel de las élites territoriales, las iglesias y los poderes locales en la configuración de la red aldeana (BROGIOLO 2005).

En el caso alavés los datos arqueológicos probablemente no permiten aún resolver adecuadamente el problema en ausencia de excavaciones en extensión de un número mayor de aldeas. Pero los datos disponibles nos llevan a dudar de la "espontaneidad" del fenómeno. Probablemente sea la definitiva instauración de poderes a nivel supralocal (a media escala) lo que permita la reorganización del espacio rural en aldeas. Hasta que no se produce la constitución efectiva de esos poderes y que se alcanza un grado de consenso y legitimidad reconocida de esas jerarquías dentro de un marco territorial amplio es impensable la existencia de una red de aldeas estable. Probablemente deberíamos insertar este proceso en el marco de la construcción y consolidación de poderes supralocales o regionales quizás vinculados a la naciente monarquía asturiana (QUIRÓS CASTILLO, VIGIL ESCALERA, 2006).
En cuarto lugar, otra constatación que se puede realizar es que a partir del siglo IX-X es evidente la presencia en el seno de las aldeas de poderes locales que han condicionado la estructura social de las mismas. La introducción de las iglesias a partir del IX-XI o fenómenos como la privatización y fijación de determinados espacios residenciales en el marco de un urbanismo cambiante nos muestran la presencia pero no la naturaleza de estos poderes locales. Este dato es de una importancia central a la hora de comprender fenómenos como el de la "feudalización" o la formación de poderes señoriales. Es a partir de este período cuando comienzan a manifestarse desequilibrios propios de la competencia por un territorio ya completamente ocupado y parcelado, de manera que surgen disputas por unos recursos finitos. Sería por lo tanto un proceso de capilarización del poder, en el que surgen las facciones locales a nivel aldeano como consecuencia de la rivalidad o competencia entre elites bien asentadas.

Un ulterior momento de reorganización de estas aldeas tuvo lugar tras el año mil, mediante la promoción de algunos templos al estatuto parroquial, y la reordenación de los espacios domésticos, que ahora se hacen más compactos y estables (QUIRÓs CASTILLO 2003).

En síntesis, aunque los datos arqueológicos son aún parciales, sugieren la existencia de una realidad muy estructurada y articulada que cuestionan la existencia y el significado del poblamiento disperso en la Alta Edad Media. El papel de distintos tipos de poderes locales ha sido muy relevante probablemente en la ordenación del espacio en el siglo VIII; en la propia evolución de las aldeas en los siglos IX-XI con la aparición en el seno de las mismas de estos poderes, y en la reordenación del urbanismo aldeano durante los siglos XI-XII cuando se pasa de un urbanismo alveolar a un urbanismo compacto en el marco de estructuras señoriales mucho más orgánicas.

En todo caso, las nuevas excavaciones en extensión que se han programado para los próximos años en aldeas y despoblados alaveses deberán perfilar y matizar muchas de las complejas implicaciones que plantea su estudio. 


\section{BIBLIOGRAFIA}

AA.V., 1983, Museo de Arqueología de Álava, VitoriaGasteiz

AA. W., 1998, El poblamiento altomedieval galaico-asturleonés: herencia prerromana, romana y visigoda, Studia Historica. Historia Medieval 16, pp. II-197

AGORRETA J. A., LLANOS A., APELLÁNIZ J. M., FARIÑA J., 1975, Castro de Berbeia (Barrio-Álava). Memoria de excavaciones de 1972, Estudio de Arqueología Alavesa 8, pp. 22I-292

AJAMIL BAÑOS F. J., 2003, Lope López de Ayala, en Rivabellosa (Ribera Baja), Arkeoikuska 2002, pp. 30I-303

AJAMIL BAÑOS F. J., 2005, Iglesia y necrópolis de San Martín de Rivabellosa (Ribera Baja); Arkeoikuska 2004, pp. |95-20|

ALONSO J. F., CASTELLET S., FERNÁNDEZ E., 19921993, La necrópolis de San Martín de Valparaíso (Villanueva de Valdegobia, Álava), Kobie XX, pp. 157-I86

APELLANIZ GONZÁLEZ J. A., 1999, Convento de Padres Capuchinos (Laguardia), Arkeoikuska 98, pp. 200-208

APELLANIZ GONZÁLEZ J. A., 200 I, Enrique IV, I de Rivabellosa (Ribera Baja), Arkeoikuska 00, pp. 147-I53

APELLANIZ GONZÁLEZ J. A., AJAMIL BAÑOS F. J., 1998, Finca Mavilla (Estavillo. Armiñón), Arkeoikuska 97, pp. 209-213

ARMENDÁRIZ A., 1986-1994, Antón Kaboa (Oñate, Guipúzcoa), Arkeoikuska 85, pp. 44-46; 86, p.40; 87, pp. 34-36; 88, pp. 40-41; 89, pp. 98-99; 90, pp. 76-80; 91, pp. 98-100; 92, pp. 190-193; 93, pp. 172-178

ARIÑO GIL E., RIERA MORA S., RODRÍGUEZ HERNÁNDEZ J., 2002, De Roma al Medievo. Estructuras de hábitat y evolución del paisaje vegetal en el territorio de Salamanca, Zephyrus 55, pp. 283-309

ARIÑO GIL E., GURT ESPARRAGUERA J. M., PALET MARTÍNEZ J. M., 2004, El pasado presente. Arqueología de los paisajes en la Hispania romana, Barcelona

AZKARATE GARAI OLAUN A., 1988, Arqueología Cristiana de la Antigüedad Tardía en Álava, Guipúzcoa y Vizcaya, Vitoria-Gasteiz

AZKARATE GARAI OLAUN A., 2000-2005, Catedral de Santa María (Vitoria-Gasteiz), Arkeoikuska 01, pp. I79I87; 02, pp. 197-203; 04, pp. 206-210

AZKARATE GARAI OLAUN A., 2004, El País Vasco en los siglos inmediatos a la desaparición del Imperio Romano, en Historia del País Vasco. Edad Media (siglos V-XV), San Sebastián, pp. 23-50

AZKARATE GARAI OLAUN A., FERNÁNDEZ DE JÁUREGUI A., NUÑEZ J., 1995, Documentación y análisis arquitectónico en el País Vasco. Algunas experiencias llevadas a cabo en Álava-España, Informes de la Construcción 46, n. 435, pp. 65-78
AZKARATE GARAI OLAUN A., SOLAÚN J. L., 2003, Después del Imperio Romano y antes del año mil: morfología urbana, técnicas constructivas y producciones cerámicas, Arqueología de la Arquitectura 2, pp. 37-46

AZKARATE GARAI-OLAUN A., NUÑEZ J., SOLAUN J., 2003, Materiales y contextos cerámicos de los siglos VI al $X$ en el País Vasco, en L. CABALLERO, P. MATEOS, M. RETUERCE (eds.), Cerámicas tardorromanas y altomedievales en la Península Ibérica. Ruptura y continuidad, Madrid, pp. 321-370

AZKARATE GARAI-OLAUN A., QUIRÓS CASTILLO J. A., 200 I, Arquitectura doméstica altomedieval en la Península lbérica. Reflexiones a partir de las excavaciones arqueológicas de la catedral de Santa María de Vitoria-Gasteiz, Archeologia Medievale XXVII, pp. 25-60.

AZKARATE GARAI-OLAUN A., ZAPATA L., 2006, Agricultura altomedieval en Vitoria-Gasteiz: la aportación de la arqueobotánica, en Jomades sobre Sistemas Agraris, Organització Social i Poder Local, Lleida, en prensa

BALDEÓN A. GARCÍA E. (coord), 1994, Arqueología de urgencia en Álava, 1989-1993, Vitoria-Gasteiz

BALDEÓN A., SÁNCHEZ SIERRA M. J., 2003, En torno a los depósitos de hoyos: avance al estudio de Santa María de Estarrona, Estudios de Arqueología Alavesa 20, pp. $42-52$

BARCELÓ M., 1988, La arqueología extensiva y el estudio de la creación del espacio rural, en Arqueología Medieval. En las afueras del "medievalismo", Barcelona, pp. 196202

BARCELÓ M., 1994, Rigor y "milongueras pretensiones". ¿Es posible historiar el feudalismo sin la Arqueología? El caso catalán, Arqueología y territorio medieval I, pp. 129139

BARCELÓ M., 1995, Crear, disciplinar y dirigir el desorden. La renta feudal y el control del proceso de trabajo campesino: una propuesta sobre su articulación, Taller d'Història VI, 2, Valencia, pp. 6I-72.

BARRIOS GARCÍA A., MARTÍN VISO I., 2000-200I, Reflexiones sobre el poblamiento rural altomedieval en el Norte de la Península Ibérica, Studia Historica. Historia Medieval 18-19, pp. 53-83

BENGOETXEA REMENTERIA B., SOLAÚN BUSTINZA J. L., 2000, Estudio Histórico-Arqueológico de la villa de Salinillas de Buradón (Labastida), Arkeoikuska 99, pp. I-29

BERGER J.-F., 200 I, Évolution des agro-et des hydrosystèmes dans la Région Médio-Rhodanienne, en P. OUZOULIAS, C. PELLECUER, C. RAYNAUD, P. GARMY (dir.), Les campagnes de la Gaule à la fin de l'Antiquité, Antibes, pp. 369-403

BONIN T., 2000, Le site de Chessy et l'occupation du sol en Île-de-France (Vie-Xe siècles). Archéologie Médiévale XXIX, pp. I-68 
BROGIOLO G. P., 2005, Risultati e prospettive della ricerca archeologica sulle campagne altomedievali italiane, en G. P. BROGIOLO, A. CHAVARRIA, M. VALENTI (eds.), Dopo la fine delle ville. Le campagne dal VI al IX secolo, Mantova, pp. 7-16

BROGIOLO G. P., CHAVARRÍA A., 2005, Aristocrazie e campagna nell'Occidente da Costantino a Carlo Magno, Firenze.

CANTERA Y BURGOS F., 1998, Fuero de Miranda de Ebro. Edición crítica, versión y estudio, Miranda de Ebro

CASTELLANOS S., VISO I. M., 2005, The local articulation of central power in the north of the Iberian Peninsula (500-1000), Early Medieval Europe 13 (1), pp. I-42.

CATTEDDU I., 200I, Les habitats carolingiens de Montours et la Chapelle-Saint-Aubert (Ille-et-Vilaire). Archéologie preventive-Autoroute A84, Paris

CHAPELOT J., FOSSIER R., 1980, Le village et la maison au Moyen Âge, Paris

CHAVARRIA A., 200I, Villae y necrópolis en Hispania durante la Antigüedad tardía, Bulletin de l'Association pour I'Antiquité tardive 10, pp. 44-57

CHAVARRIA A., 2004, Interpreting the transformation of Late Roman Villas. The case of Hispania, en N. CHRISTIE, Landscape of change. Rural evolutions in Late Antiquity and the Early Middle Ages, Cornwall, pp. 67-102

COLARDELLE M., VERDEL E., 1993, Les habitats du lac de Paladru (Isère) dans leur environnement : la formation d'un terroir au Xle siècle, Paris

COLLINS R., 2005, La España visigoda, 409-7II, Historia de España IV, Barcelona

CONTE P., 1995, L'archéologie des silos médiévaux Apports, limites et perspectives, Histoire et Sociétés Rurales 3, pp. 190-201

CUISINIER J., GUADAGNIN R. (eds.), 1988, Un village au temps de Charlemagne. Moines et paysans de l'abbaye de Saint-Denis du VII siècle à l'An Mil, Paris

DAVITE C., MORENO D., 1996, Des "Saltus" aux "Alpes" dans les Apennins du Nord (Italie). Una hypothèse sur la phase du Haut Moyen Age (560-680 AP J.-C.) dans le diagramme pollinique du site de Prato Spilla, en L'homme et la nature au Moyen Age. Paléoenvironnement des sociétés occidentales, Actes du Ve congrès international d’Archéologie Médiévale, Grenoble 1993, Paris, pp. 138142

ELORZA J. C., 1970, De epigrafía cristiana alavesa, Estudios de Arqueología Alavesa 4, pp. 283-291

FERNÁNDEZ BORDEGARAY F. 1., 1992-1995, El Castillo de Portilla (Zambrana), Arkeoikuska 91, pp. 62-64, 92, pp. 100-106; 93, pp. 84-91; 94, pp. 99-107

FERNÁNDEZ BORDEGARAY F. I., 1998, Manzanas de casas I y IV del Casco Histórico de Vitoria-Gasteiz, Arkeoikuska 97, pp. 221-228
FERNÁNDEZ BORDEGARAY F. .., 2005, Cuchillería, 54B I Tintorería s/n y 33 (Vitoria-Gasteiz), Arkeoikuska 2004, pp. $219-223$

FERNÁNDEZ ERASO ।., 2000-2002, Abrigo de Los Husos I (Elvillar), Arkeoikuska 99, pp. 44-48; 00, p. 39-45; 0I, pp. 68-73

FERNÁNDEZ ERASO J., 2005-2006, Abrigo de Los HusosII (Elvillar), Arkeoikuska 01, pp. 73-76; 04 pp. 65-68; 05 pp. 59-62

FERNÁNDEZ MIER M., 1999, Génesis del territorio en la edad Media. Arqueología del paisaje y evolución histórica en la montaña asturiana, Oviedo

FERNÁNDEZ UGALDE A., 1993, El relleno de silos y la implantación del feudalismo en Madrid y en el Reino de Toledo, en IV Congreso de Arqueología Medieval Española, vol. 3, pp. 6||-6|8

FERNÁNDEZ UGALDE A., 1997, El almacenamiento subterráneo y la conquista feudal en la Península Ibérica: aportaciones de la arqueología, en Rural Settlements in Medieval Europe, Papers of the Medieval Europe Brugge 1997, Brujas, Vol. 6, pp. 283-289

FILLOY NIEVA I., 1999, Construcción de balsas y red de riego para $1.000 \mathrm{Ha}$. (Peñacerrada-Urizaharra), Arkeoikuska 98, pp. 304-31।

FILLOY NIEVA I., GIL ZUBILLAGA E., 2000, La romanización en Álava. Catálogo de la exposición permanente sobre Álava en época romana en el Museo de Arqueología de Álava, Vitoria-Gasteiz

FOSSIER R., 1984, La infancia de Europa. Aspectos económicos y sociales. 2 vols. Barcelona

FOSSIER R., 1996, La sociedad medieval, Barcelona

FRANCOVICH R., 2004, Villaggi dell'altomedievo: invisibilità sociale e labilità archeologica, en M. VALENTI, L'insediamento altomedievale nelle campagne toscane, Florencia, pp. $|X-X X| \mid$

FRANCOVICH R., HODGES R., 2003, Villa to villages. The transformation of the Roman Countryside in Italy, c. 4001000, London

FRANCOVICH R., HODGES R., 2004, Campionando un villaggio medievale: Montarrenti fra storia e archeologia, en F. CANTINI, II castello di Montarrenti, Florencia, pp. 9-22

FRANCOVICH R., MILANESE M., 1989, Lo scavo archeologico di Montarrenti e i problema dellincastellamento medievale. Esperienze a confronto, Florencia

GARCÍA CAMINO I., 2002, Arqueología y poblamiento en Bizkaia, siglos VI-XII. La configuración de la sociedad feudal, Diputación Foral de Bizkaia, Bilbao

GARCÍA DE CORTAZAR J. A., 1981, La organización del territorio en la formación de Álava y Vizcaya en los siglos VIII a fines del XI, en El hábitat en la historia de Euskadi, Bilbao, pp. I33- I55 (ahora en Investigaciones sobre la Historia Medieval del País Vasco (1 965-2005), Bilbao, pp. 203236) 
GARCÍA DE CORTAZAR J. A., 1982, La sociedad alavesa medieval antes de la concesión del fuero de Vitoria, en Vitoria en la Edad Media, Vitoria, pp. 89-1I6 (ahora en Investigaciones sobre la Historia Medieval del País Vasco (1965-2005), Bilbao, pp. 313-362)

GARCÍA DE CORTAZAR J. A., 1983, Los oscuros comienzos. La Alta Edad Media, en Álava en sus manos, fasc. 20, tomo III, Vitoria, pp. 73-I04

GARCÍA DE CORTAZAR J. A., 1985, Del cantábrico al Duero, en J. GARCÍA DE CORTAZAR et alii, Organización social del espacio en la España medieval. La Corona de Castilla en los siglos VIII al XV. Barcelona, pp. 43-83

GARCÍA DE CORTAZAR J. A., 1988, La sociedad rural en la España Medieval, Madrid

GARCÍA DE CORTAZAR J. A., 1999, Poblamiento y modelos de sociedad en la transición de la Antigüedad al feudalismo entre el Cantábrico y el Duero, Sautuola VI, pp. 50l-5। I

GARCÍA RETES E., 1987, El camino de San Adrián (Guipúzcoa-Álava) en la ruta jacobea. Análisis documental y arqueológico, Estudios de Arqueología Alavesa I5, pp. 355497.

GAST M., SIGAUT F., 1979, Les techniques de conservation de grains à long terme. Leur rôle dans la dynamique des systèmes de cultures et des sociétés, Paris

GIL ZUBILLAGA E., 1997, El poblamiento en el territorio alavés en época romana, Isturitz 8, pp. 23-52

GIL ZUBILLAGA E., 1998, Plaza de Santa María I, (Vitoria-Gasteiz), Arkeoikuska 99, pp. 175-181

GIL ZUBILLAGA E., 1999, C/Álava en Nanclares de la Oca (Iruña de Oca), Arkeoikuska 1998, pp. 299-30 I

GIL ZUBILLAGA E., 2003, Ciudad de Iruña/Veleia (Iruña de Oca), Arkeoikuska 2002, pp. 239-242

GIL ZUBILLAGA E., 2003-2004, Ciudad de Iruña/Veleia. Domus del impluvium A (Iruña de Oca), Arkeoikuska 2002, pp. 54-61; 2003, pp. 69-73

GIL ZUBILLAGA E., 2005, Ciudad de Iruña / Veleia (Iruña de Oca), Arkeoikuska 2004, pp. 63-67

GIL ZUBILLAGA L., 1997, Despoblado de Reñanilla (Elvillar), Arkeoikuska 96, pp. 67-70

GIL ZUBILLAGA L., 1997, Hábitat tardorromano en cuevas de la Rioja Alavesa: los casos de Peña Parda y Los Husos I (Laguardia, Álava), Isturitz 8, pp. 23-52

GIL ZUBILLAGA L., 1998-1999, Yacimiento del Pago de Eskide (Yécora), Arkeoikuska 97, pp. 108- I I I; 98, pp. 8081

GIL ZUBILLAGA L., 1999, Poblamiento romano y medieval en la Sonsierra de la Rioja: Prospecciones y catas arqueológicas (1997-1998), Estrato. Revista riojana de arqueología 10, pp. 73-79.
GIL ZUBILLAGA L., 200I, Necrópolis de San Roque de Acebedo (Valdegobía), Arkeoikuska 00, pp. I53-I55

GIL ZUBILLAGA L., 200I, Seguimiento arqueológico de las obras del regadío de la Sonsierra: Excavación de los yacimientos de Las Sepulturas y San Pablo, Estrato. Revista riojana de arqueología 13, pp. 93-101.

GIL ZUBILLAGA L., 2005, Los silos de La Llana (Labastida, Álava): Memoria de las campañas de excavación de 1995, 1996 y 1997, en Estudios de Arqueología Alavesa 21, pp. 28I-309

GIL ZUBILLAGA L., SÁENZ DE URTURI P., 200I, San Miguele. La necrópolis tardoantigua y altomedieval de San Miguele (Molinilla, Álava). Memoria de las excavaciones arqueológicas de 1998 y de la intervención de urgencia de 1981, Vitoria-Gasteiz

HAMEROW H., 2002, Early Medieval Settlements. The Archaeology of Rural Communities in Northest Europe, AD 400-900, Oxford

JUSUÉ SIMONENA C., 1998, Poblamiento rural en Navarra en la Edad Media. Bases arqueológicas. Valle de Urraul Bajo, Pamplona

LARREA J. J., 1998, La Navarre du IVe au Xlle siècle. Peuplement et société, Bruxelles

LECANDA J. A., 2000, Mijangos : la aportación de la epigrafía y el análisis arqueológico al conocimiento de la transición a la Alta Edad Media en Castilla, en L. CABALLERO, P. MATEOS (eds.), Visigodos y Omeyas. Un debate entre la Antigüedad y la Alta Edad Media, Madrid, pp. 18|-206

LLANOS A. (dir), 1987, Carta Arqueológica de Álava (hasta 1984), Vitoria-Gasteiz

LLANOS A., APELLANIZ J. M., AGORRETA J. A., FARIÑAS J., 1975, El castro del Castillo de Henayo (Alegria-Alava). Memorias de excavaciones. Campaña de excavaciones 1969-1970, Estudios de Arqueología Alavesa 5, pp. $87-212$

LLANOS A., FERNÁNDEZ DE MEDRANO D., 1968, Necrópolis de hoyos de incineración en Álava, Estudios de Arqueología Alavesa III, pp. 45-72

LÓPEZ DE GUEREÑU GALÁRRAGA G., 1962, Alava, solar de arte y fé, Vitoria

LÓPEZ DE GUEREÑU GALÁRRAGA G., 1989, Toponimia alavesa seguido de Mortuorios o despoblados y Pueblos alaveses, Bilbao

LÓPEZ QUIROGA J., 2004, El final de la Antigüedad en la Gallaecia. La transformación de las estructuras de poblamiento entre Miño y Duero (siglos V al X), Santiago

LORREN C.., PERIN P. (eds.), 1995, L'habitat rural du Haut Moyen Âge (France, Pays-Bas. Danemark et Grande-Bretagne), Saint-Germain-en-Laye.

MARINA LÓPEZ R., 1996, Análisis tipológico y funcional del entramado subterráneo - cueva de Laguardia (Álava), informe inédito 
MONREAL JIMENO L. A., 1989, Eremitorios rupestres altomedievales (el alto valle del Ebro), Universidad de Deusto

MORAZA BAREA A., MÚJICA ALUSTIZA J. A., 2006, Establecimientos de habitación al aire libre. Los fondos de cabaña de morfología tumular: características, proceso de formación y cronología, Veleia (en prensa)

NÚÑEZ MARCÉN J., SAÉNZ DE URTURI P., 2005, Una mutatio de la vía Ab Asturica Burdigalam en Mariturri (Vitoria / Álava), Archivo Español de Arqueología 78, pp. | 89-207

PALET MARTÍNEZ I. M., RIERA MORA S., 1994, Landscape dynamics from Iberian-Roman (2nd- Ist centuries BC) to Early Medieval times (12th century) in the Montjuïc-El Port Sector (Plain of Barcelona, NE Iberian Peninsula), Archeologia Medievale XXI, pp. 517-540

PALOL P., 197I, Los objetos visigodos de la cueva de Los Goros (Hueto de Arriba- Álava), en Investigaciones Arqueológicas en Álava (1957-1968), Vitoria, pp. 25-32

PASTOR DÍAZ DE GARAYO E., 1986, Salvatierra y la Ilanada oriental alavesa (siglos XIII-XV), Vitoria-Gasteiz.

PASTOR DÍAZ DE GARAYO E., 1988, Aproximación a la estructura del poblamiento alavés a finales del siglo XIII, en II Congreso Mundial Vasco. Congreso de Historia de Euskal Herria, tomo II Antigüedad y Edad Media, pp. 277-295

PASTOR DÍAZ DE GARAYO E., 1996, Castilla en el tránsito de la Antigüedad al Feudalismo. Poblamiento, poder político y estructura social del Arlanza al Duero (siglos VII$X I$ ), Valladolid

PASTOR DÍAZ DE GARAYO E., 2006, La Llanada oriental hace mil años iqué hay del crecimiento agrario altomedieval?, en Actas del Congreso 750 aniversario de la fundación de la villa de Salvatierra, San Sebastián (en prensa)

PEÑA BOCOS E., 1995, La atribución social de espacio en la Castilla Altomedieval. Una nueva aproximación al feudalismo peninsular, Santander

PEÑA CHOCARRO L., ZAPATA L., GONZÁLEZ URQUIJO J. E., IBÁÑEZ ESTEVEZ J. J., 2000, Agricultura, alimentación y uso de combustible: aplicación de modelos etnográficos en arqueobotánica, Saguntum Extra 3", pp. $403-420$

PEYTREMANN E., 2003, Archéologie de l'habitat rural dans le nord de la France du IVe au XIle siècle, Saint-Germainen-Laye.

QUIROS CASTILLO J. A., 1998, Cambios y transformaciones en el territorio del Apenino Toscano entre la Antigüedad Tardía y la Edad Media. El castaño, Archeologia Medievale. Cultura Materiale, Insediamenti, Territorio XXV, pp. 177-197.

QUIRÓS CASTILLO J. A., 2003, La Llanada oriental entre la tardoantiguedad y el año mil: las transformaciones en la estructura del hábitat y del poblamiento rural, en E. PASTOR DÍAZ DE GARAYO (coord.), La llanada oriental a través de la historia: claves desde el presente para comprender nuestro pasado, Diputación Foral de Álava, Vitoria, 2003, pp. 43-5।
QUIRÓS CASTILLO J. A., 2006, De la aldea a la villa: Arqueología de los despoblados en la llanada oriental alavesa. El caso de Zornoztegi, en Actas del Congreso 750 aniversario de la fundación de la villa de Salvatierra, San Sebastián (en prensa)

QUIRÓS CASTILLO J. A., BENGOETXEA REMENTERIA B., 2005, Las villas vascas antes de las villas vascas. La perspectiva arqueológica sobre la génesis de las villas en el País Vasco, en B. ARIZAGA (ed.), El espacio urbano en la Europa medieval, Nájera, pp. I47-I65

QUIRÓS CASTILLO I. A., BENGOETXEA REMENTERIA B., 2006, Arqueología (III) (Arqueología postclásica), Unidades Didácticas, UNED, Madrid

QUIRÓS CASTILLO J. A., VIGIL ESCALERA A., 2006, Network of peasant villages between Toledo and Uelegia Alabense, Northwestern Spain (V-Xth centuries), Archeologia Medievale XXXIII, en prensa

RENDU C., 2003, La montagne d'Enveig. Une estive pyrénéenne sans la longue durée. Canet.

RIAÑO PÉREZ E., 1995, Eremitorios rupestres y colonización altomedieval, Studia Historica. Historia Medieval I3, pp. $47-58$

RIGOIR J., RIGOIR Y., MEFFRE J. F., 1973, Les dérivés des sigillés paléochrétiennes du groupe atlantique, Gallia. Fouilles et monuments archéologiques en France métropolitaine 31, I, pp. 207-263

SAENZ DE URTURI F., 1982-1998, Poblado de Los Castros de Lastra (Caranca, Valdegobía), Arkeoikuska 81-82, pp. |6-17; 83, pp. |8-19; 84, pp. 24-26; 85, pp. 28-30; 86, pp. 28-31; 87, pp. 24-27; 88, pp. 24-27; 89, pp. 3538; 90, pp. 22-26; 91, pp. 39-44; 92, pp. 52-57; 93, pp. 53-62; 94, pp. 93-98; 97, pp. 90-95

SÁENZ DE URTURI F., 1993, Ansoleta-Olarizu (VitoriaGasteiz), Arkeoikuska 1992, pp. 289-29|

SAÉNZ DE URTURI F., 1994, Urbanización del polígono industrial de Ansoleta, en Arqueología de urgencia en Alava, 1989-1993, Vitoria-Gasteiz, pp. 25-28

SÁENZ DE URTURI RODRÍGUEZ F., 1990, Memoria de los sondeos estratigráficos realizados en las inmediaciones de las "Cuevas de los Moros" (Corro-Álava), Estudios de Arqueología Alavesa 17, pp. 179-219

SÁENZ DE URTURI RODRÍGUEZ F., 1997, EI Despoblado de Legardagutxi (Lermanda, Álava). Aproximación a su estudio ceramológico, en XXIV Congreso Nacional de Arqueología, vol.5., Cartagena, 1997.

SCHNEIDER L., 1992, Habitat et genèse villageoise du Haut Moyen Age. L'exemple d'un terroir du Biterrois nord-oriental, Archéologie du Midi Médiéval X, pp. 3-37

SOLAUN BUSTINZA J. L., SÁNCHEZ PINTO I., 2003, Castillo de Ocio (Zambrana), Arkeoikuska 2002, pp. 209221

SOLAUN BUSTINZA J. L., 2006, La cerámica medieval en el País Vasco (siglos VIII-XIII), Vitoria-Gasteiz (en prensa) 
UGARTECHEA J. M., 1967, Notas sobre el yacimiento de Salbatierrabide (Vitoria), Estudios de Arqueología Alavesa 2 , pp. $101-118$

UNZUETA M., MARTÍNEZ A., 1994, Proyecto de variante y túnel entre las Conchas de Haro y el cruce de Briñas, en Arqueología de urgencia en Álava, 1989-1993, Vitoria-Gasteiz, pp. 43-60

URIBARRI E., 1994, Dataciones de época histórica del yacimiento en Cueva de Iritegi (Oñate, Gipuzkoa), Munibe (Antropología. Arkeologia) 46, pp. 147-152

URTEAGA M., UGALDE TX., GANDIAGA B., 1989, Prospecciones arqueológicas en Urbia: yacimientos catalogados en las campañas de 1988 y 1989, Kobie 18, pp. 123-166

URTEAGA M., UGALDE TX., GANDIAGA B., 19921993, Prospecciones arqueológicas en Urbia: yacimientos catalogados en las campañas de 1990 y 199|, Kobie 20, pp. 57-85

VALENTI M., 2004, L'insediamento altomedievale nelle campagne toscane. Paesaggi, popolamento e villaggi tra $\mathrm{VI}$ e $\mathrm{X}$ secolo, Florencia
VERA D., 1986, Forme e funzioni della rendita fondiaria nella tarda antichità, en A. GIARDINA (ed.), Società Romana e Impero Tardoantico, III, Roma, pp. 367-447

VIGIL ESCALERA A., 2003, Los poblados de época visigoda del Sur de Madrid: algunos aspectos económicos y sociales, en I Congreso del Instituto de Estudios Históricos del Sur de Madrid, Alcorcón, pp. 5I-68

VIGIL ESCALERA A., 2006, El modelo de poblamiento rural en la Meseta y algunas cuestiones de visibilidad arqueológica, en Galia e Hispania en el contexto de la presencia "Germánica" (s. V-VII). Balance y perspectivas, Madrid, en prensa

WICKHAM C., 2005, Framing the Early Middle Ages. Europe and the Mediterranean, 400-800, Oxford

ZADORA RIO E., 1995, Le village des historiens et le village des archéologues, en R. MORNET (ed.), Campagnes Médiévales : l'homme et son espace. Etude offertes à Robert Fossier, Paris, pp. 143-153

ZADORA RIO E., 2003, L'habitat rural au Moyen Age, Les nouvelles de l'archéologie 92, $2^{\circ}$ trimestre, pp. 5-34 


\begin{tabular}{|c|c|c|c|c|}
\hline MUESTRA & YAC. & DATAC. B.P. & CAL $68,2 \%$ & CAL $95,4 \%$ \\
\hline Los Husos I, nivel I & Cueva & $1818 \pm 50$ & $120-250(68,2 \%)$ & $70-340(95,4 \%)$ \\
\hline Los Husos II, nivel II inf & Cueva & $1770 \pm 50$ & $210-350(63 \%)$ & $130-390(95,4 \%)$ \\
\hline Los Husos I, nivel I & Cueva & $1760 \pm 50$ & $210-350(65,2 \%)$ & $130-390(95,4 \%)$ \\
\hline Los Husos II, nivel I & Cueva & $1610 \pm 40$ & $400-470(34,8 \%)$ & $340-550(95,4 \%)$ \\
\hline Los Husos I, nivel II & Cueva & $1600 \pm 40$ & $480-540(36,9 \%)$ & $380-560(95,4 \%)$ \\
\hline Los Husos II, nivel I & Cueva & $1570 \pm 40$ & $430-540(68,2 \%)$ & $400-580(95,4 \%)$ \\
\hline Los Husos I, nivel I & Cueva & $1560 \pm 40$ & $420-560(68,2 \%)$ & $380-640(95,4 \%)$ \\
\hline Los Husos I, nivel II & Cueva & $1550 \pm 40$ & $430-560(68,2 \%)$ & $400-610(95,4 \%)$ \\
\hline Aralar, Arrubi 3 & Braña & $1440 \pm 100$ & $530-680(58,7 \%)$ & $390-780(95,4 \%)$ \\
\hline Cueva de Iritegi, nivel VI & Cueva & $1370 \pm 80$ & $590-720(58,5 \%)$ & $530-880(95,4 \%)$ \\
\hline Los Husos II, nivel II & Cueva & $1370 \pm 40$ & $630-685(68,2 \%)$ & $590-720(90,1 \%)$ \\
\hline Aralar, Esnaurreta 21 & Braña & $1340 \pm 40$ & $640-700(57,3 \%)$ & $630-780(95,4 \%)$ \\
\hline Necrópolis Los Moros & Cueva & $1330 \pm 90$ & $610-780(66,8 \%)$ & $540-900(95,4 \%)$ \\
\hline Gasteiz, UE 18446 & Villa & $1275 \pm 34$ & $680-730(38,3 \%)$ & $660-820(93,6 \%)$ \\
\hline La Llana 2 & Braña & $1250 \pm 70$ & $680-870(68,2 \%)$ & $650-900(90,7 \%)$ \\
\hline Aralar, Uela Iparra 31 & Braña & $1240 \pm 50$ & $680-830(60,1 \%)$ & $660-890(95,4 \%)$ \\
\hline Zornoztegi, silo 1 & Despoblado & $1205 \pm 21$ & $775-830(39,9 \%)$ & $770-900(95,4 \%)$ \\
\hline Gasteiz, UE 18293 & Villa & $1155 \pm 35$ & $910-900(39,6 \%)$ & $770-980(95,4 \%)$ \\
\hline Cueva de Iritegi, nivel V & Cueva & $1150 \pm 80$ & $770-980(68,2 \%)$ & $680-1020(95,4 \%)$ \\
\hline Cueva de Iritegi, nivel V & Cueva & $1140 \pm 80$ & $800-990(65,3 \%)$ & $680-1030(95,4 \%)$ \\
\hline Aralar, Zain 3 & Braña & $1100 \pm 80$ & $890-1030(65,7 \%)$ & $760-1050(89,1 \%)$ \\
\hline Aralar, Esnaurreta 22 & Braña & $1080 \pm 40$ & $940-1020(51 \%)$ & $880-1030(95,4 \%)$ \\
\hline Aralar, Egurral 1 & Braña & $1070 \pm 50$ & $940-1020(53,1 \%)$ & $860-1050(94,3 \%)$ \\
\hline Aralar, Urrain 1 & Braña & $1060 \pm 50$ & $890-1030(68,2 \%)$ & $810-1060(88,7 \%)$ \\
\hline La Llana 1 & Despoblado & $1050 \pm 40$ & $960-1030(59,7 \%)$ & $890-1040(95,4 \%)$ \\
\hline Aralar, Bilingaratz 34 & Braña & $1040 \pm 50$ & $950-1040(58,1 \%)$ & $880-1050(86,3 \%)$ \\
\hline Sierra de Urbia, Elola II & Braña & $990 \pm 80$ & $990-1160(68,2 \%)$ & $890-1160(95,4 \%)$ \\
\hline Cueva de Iritegi, nivel IV & Cueva & $990 \pm 80$ & $990-1160(68,2 \%)$ & $890-1160(95,4 \%)$ \\
\hline Sierra de Urbia, Elola II & Braña & $990 \pm 80$ & $990-1160(68,2 \%)$ & $890-1160(95,4 \%)$ \\
\hline
\end{tabular}

Fig. I. Dataciones radiocarbónicas calibradas del territorio alavés y su entorno de época altomedieval ya editadas o en prensa. 




Fig. 2. Yacimientos tardoantiguos alaveses citados en el texto. 


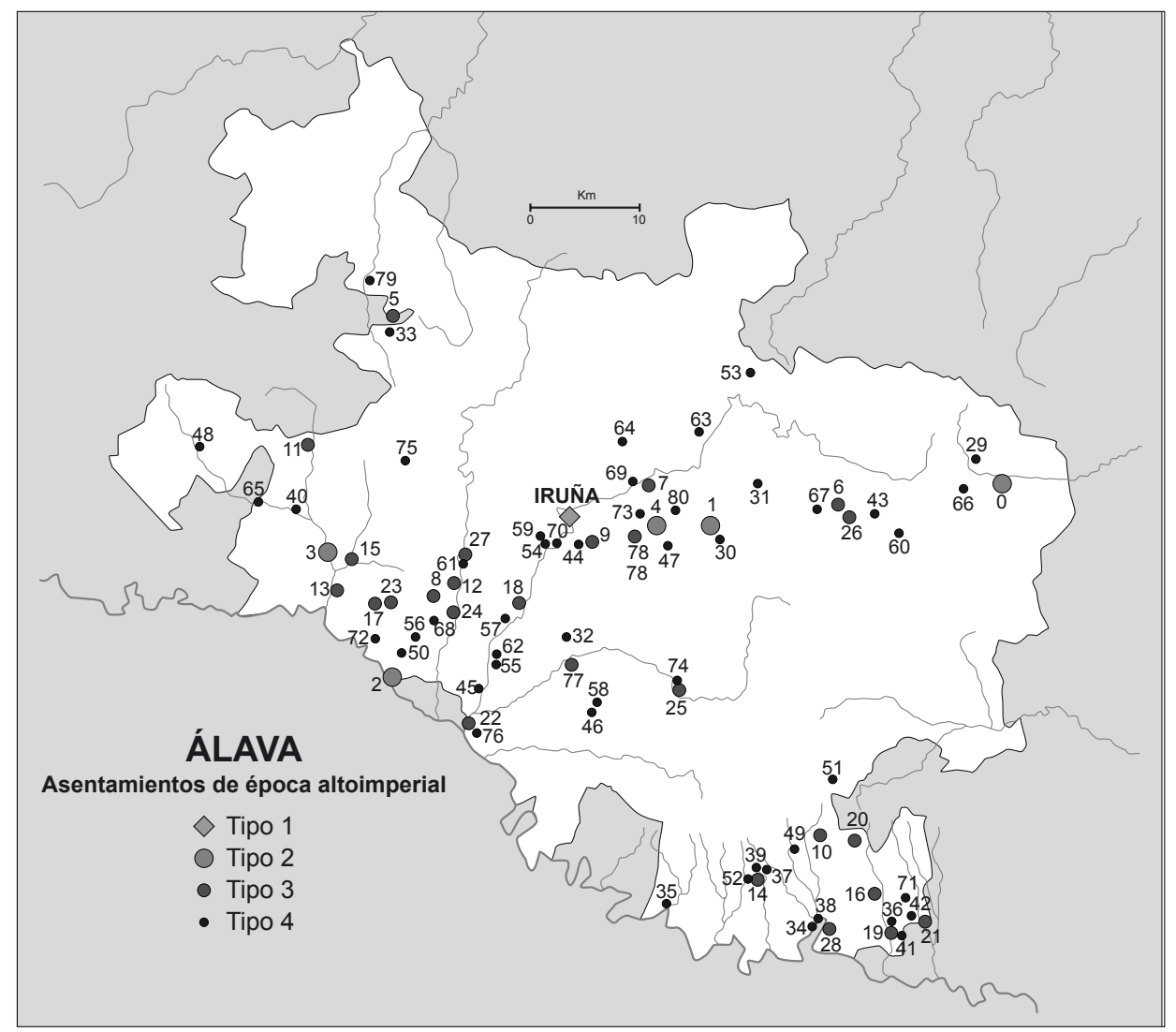

Fig. 3. Álava en el período altoimperial, según I. Filloy, E. Gil (2000).

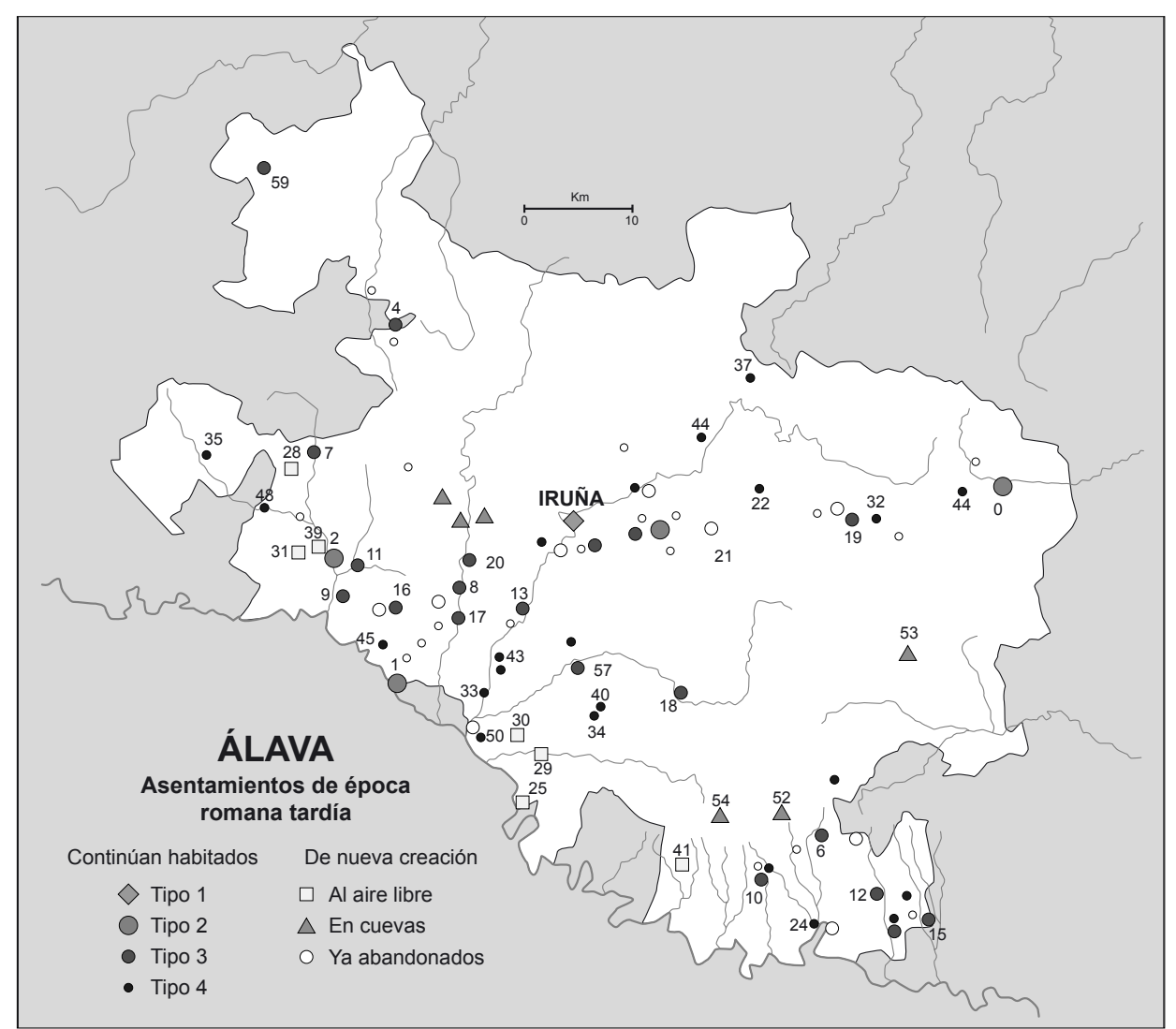

Fig. 4. Álava en el período tardorromano, según I. Filloy, E. Gil (2000). 


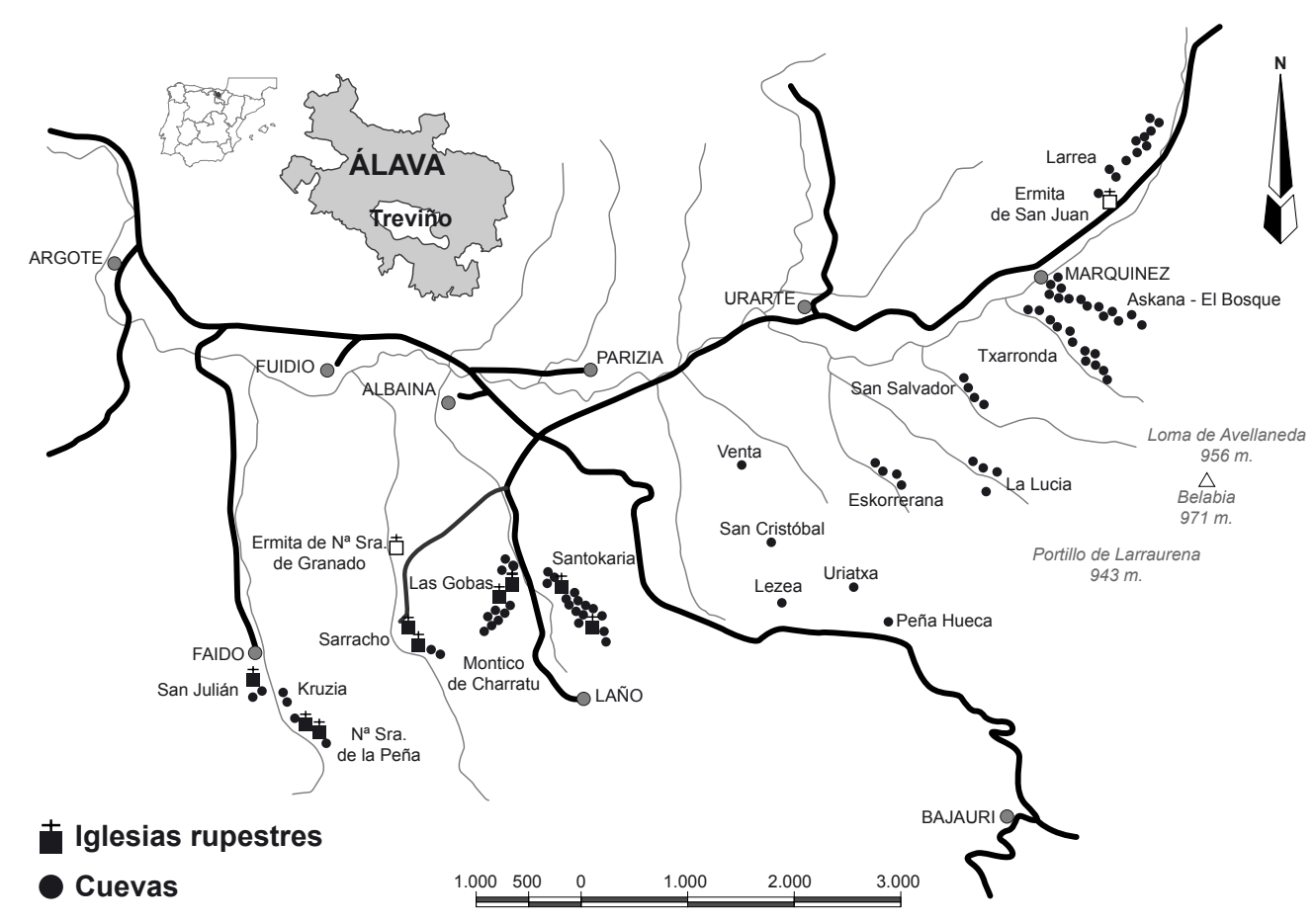

Fig. 5. Distribución de las cuevas artificiales de Álava (Treviño-Marquinez), según A. Azkarate (1988).

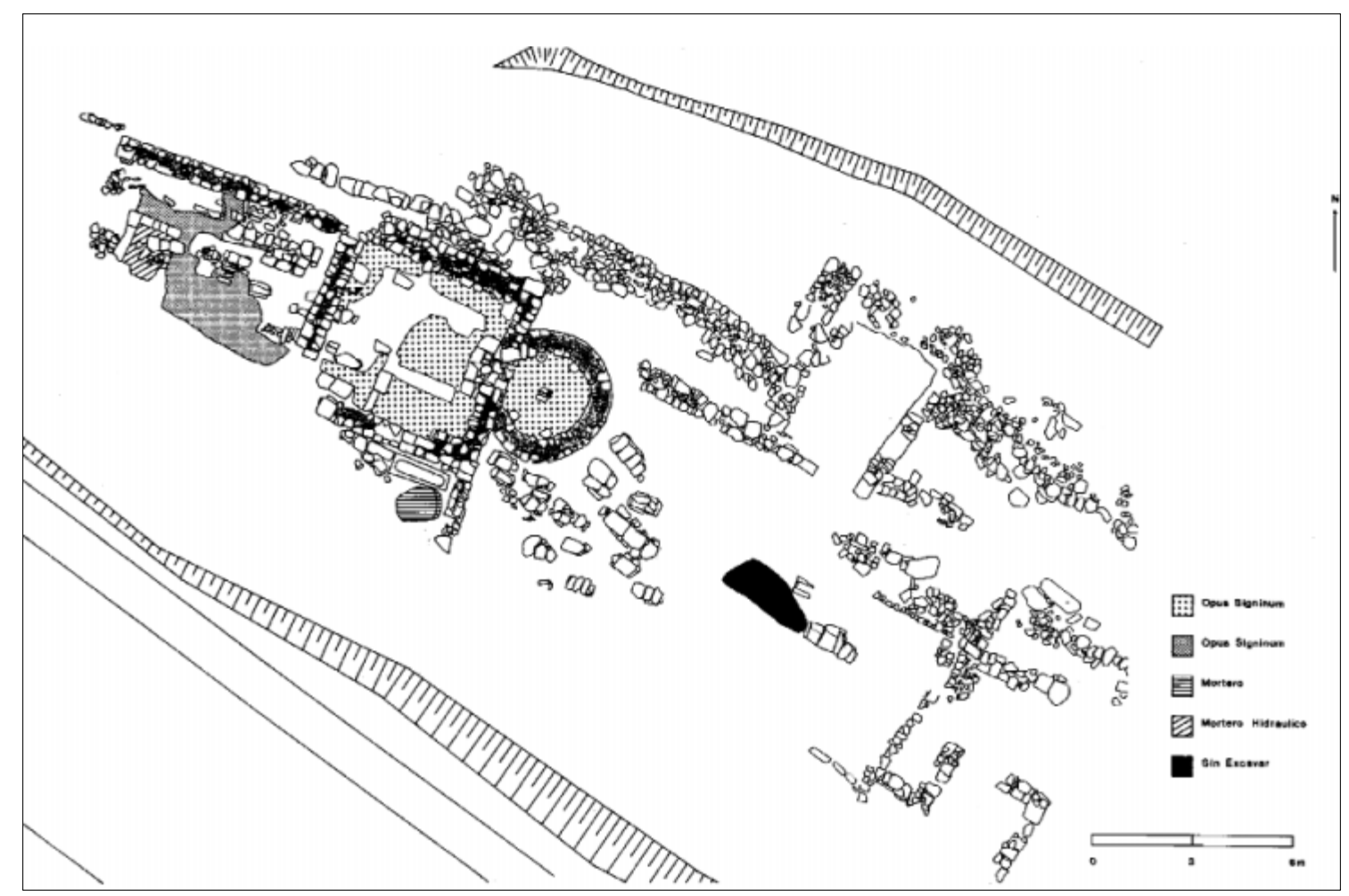

Fig. 6. Planta de la iglesia del castro de Buradón, según M. Unzueta, A. Martínez (1994). 


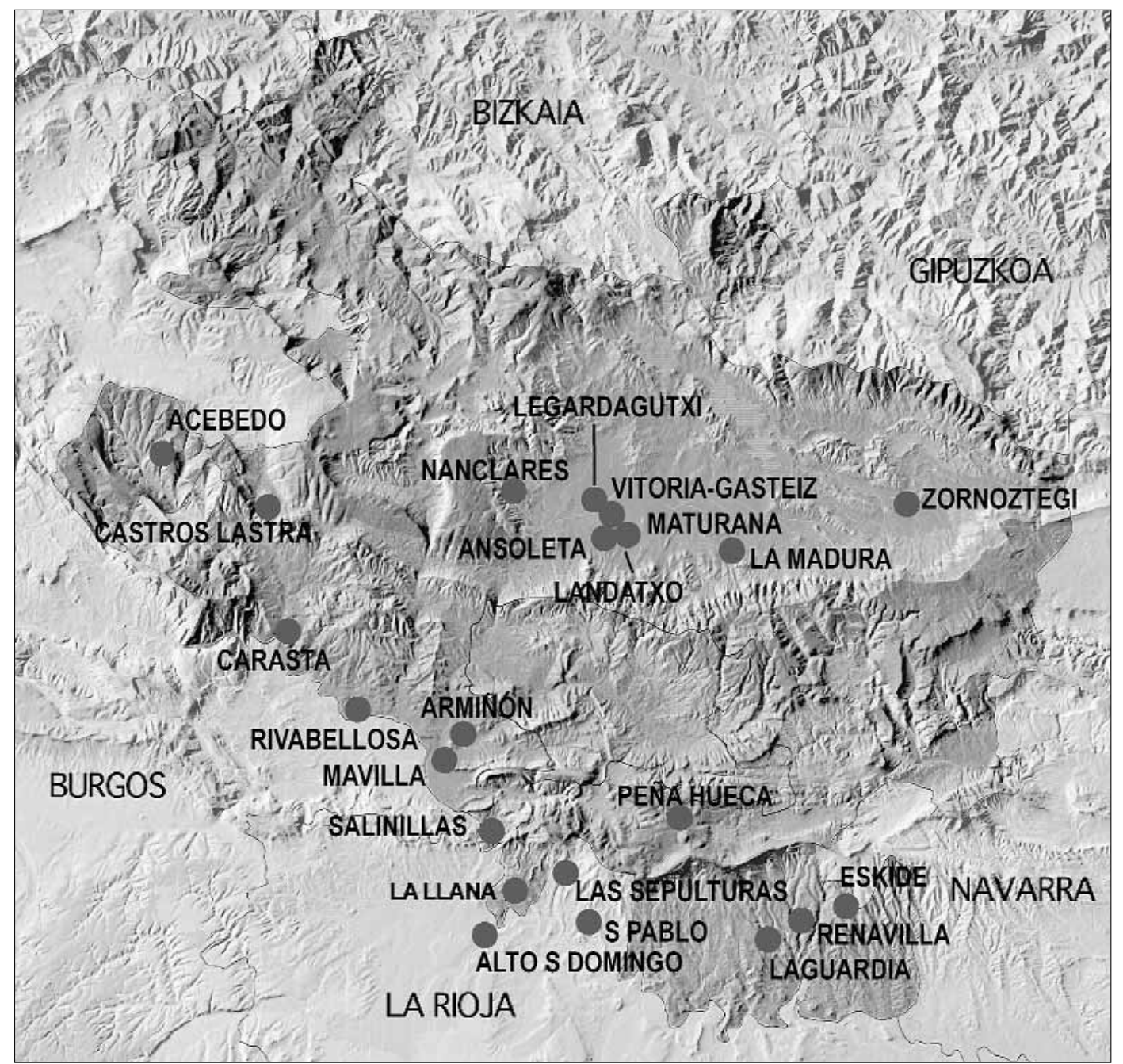

Fig. 7. Ubicación de las aldeas altomedievales estudiadas en Álava.

Fig. 8. Evolución del urbanismo aldeano en Álava: Alcedo en la actualidad (A) y en el siglo X (B), según J. A. García de Cortazar (1978).

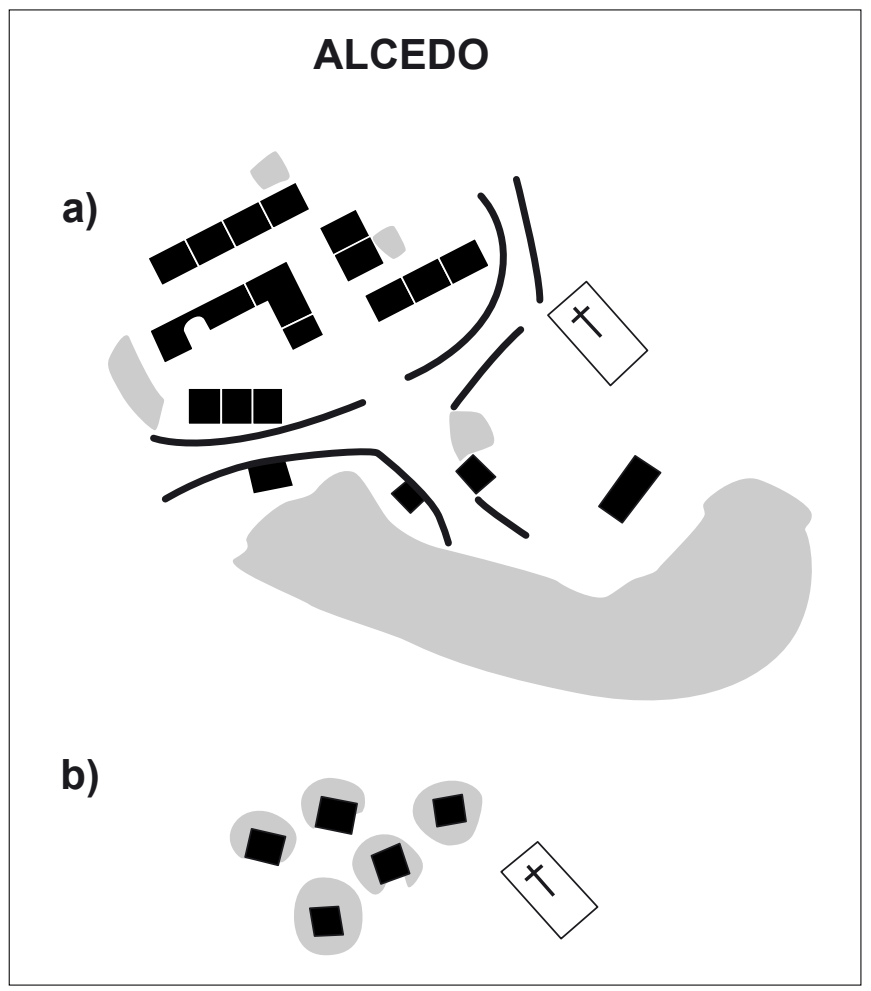




\begin{tabular}{|c|c|c|}
\hline YACIMIENTOS & TIPO DE YACIMIENTO & $\mathbf{N}^{\circ}$ DE SILOS \\
\hline Ansoleta (Vitoria-Gasteiz) & Despoblado & 2 \\
\hline Armiñón, San Andrés & Poblado & 1 \\
\hline Carasta & Despoblado & 1 \\
\hline Castros de Lastra (Valdegobia) & Despoblado & 1 \\
\hline Esquide (Yécora) & Despoblado & 0 \\
\hline Alto de Santo Domingo (Haro) & Poblado & +32 \\
\hline La Llana (Labastida) & Despoblado & 16 \\
\hline La Madura (Hijona) & Despoblado & 1 \\
\hline Laguardia & Villa & 23 \\
\hline Landatxo (Vitoria-Gasteiz) & Poblado & 3 \\
\hline Laren de Panadero (Nanclares de Oca) & Aldea & 8 \\
\hline Legardagutxi & Despoblado & 5 \\
\hline Mavilla (Estabillo) & Poblado & 17 \\
\hline Nanclares de Oca & Poblado & 1 \\
\hline $\begin{array}{l}\text { Necrópolis de Las Sepulturas } \\
\text { (San Vicente de Sonsierra) }\end{array}$ & Despoblado & 16 \\
\hline $\begin{array}{l}\text { Necrópolis de San Pablo } \\
\text { (San Vicente de Sonsierra) }\end{array}$ & Despoblado & 12 \\
\hline Peña Hueca (Peñacerrada) & Despoblado & varios \\
\hline Presaburu (Maturana) & Despoblado & 1 \\
\hline Reñanilla (Elvillar) & Despoblado & 0 \\
\hline Ribavellosa & Poblado & 16 \\
\hline Salinillas de Buradón & Villa & 1 \\
\hline San Andrés (Armiñón) & Poblado & 1 \\
\hline San Roque de Acebedo (Valdegobia) & Despoblado & 3 \\
\hline Vitoria-Gasteiz & Villa & +5 \\
\hline Zornoztegi (Salvatierra-Agurain) & Despoblado & 29 \\
\hline
\end{tabular}

Fig. 9. Número de silos excavados en aldeas alavesas con ocupaciones altomedievales. 


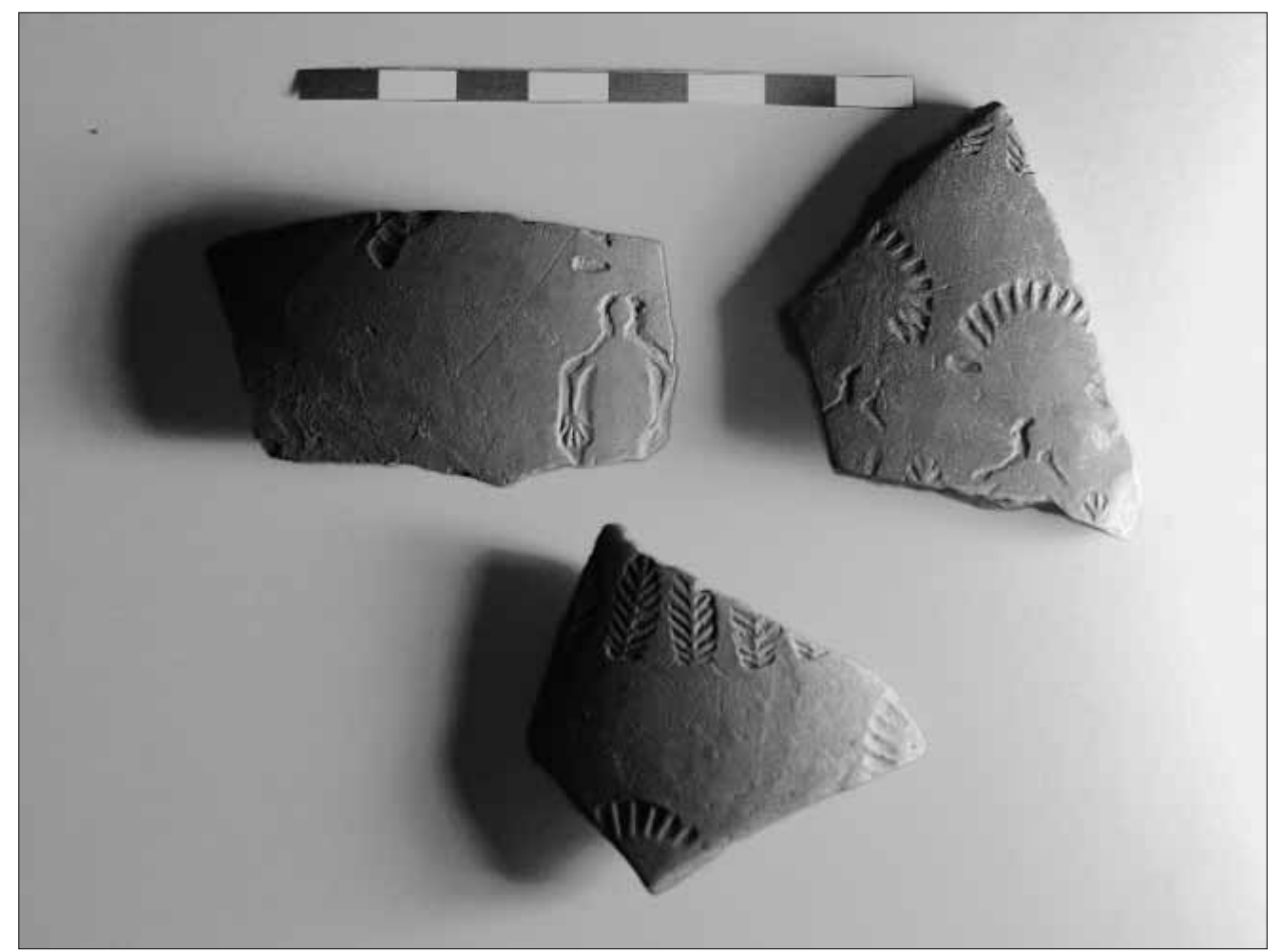

Lam. I. DSP hallada en las cuevas de los Husos (Laguardia), fechadas en la segunda mitad del siglo V-inicios VI, según J. Fernández Eraso.

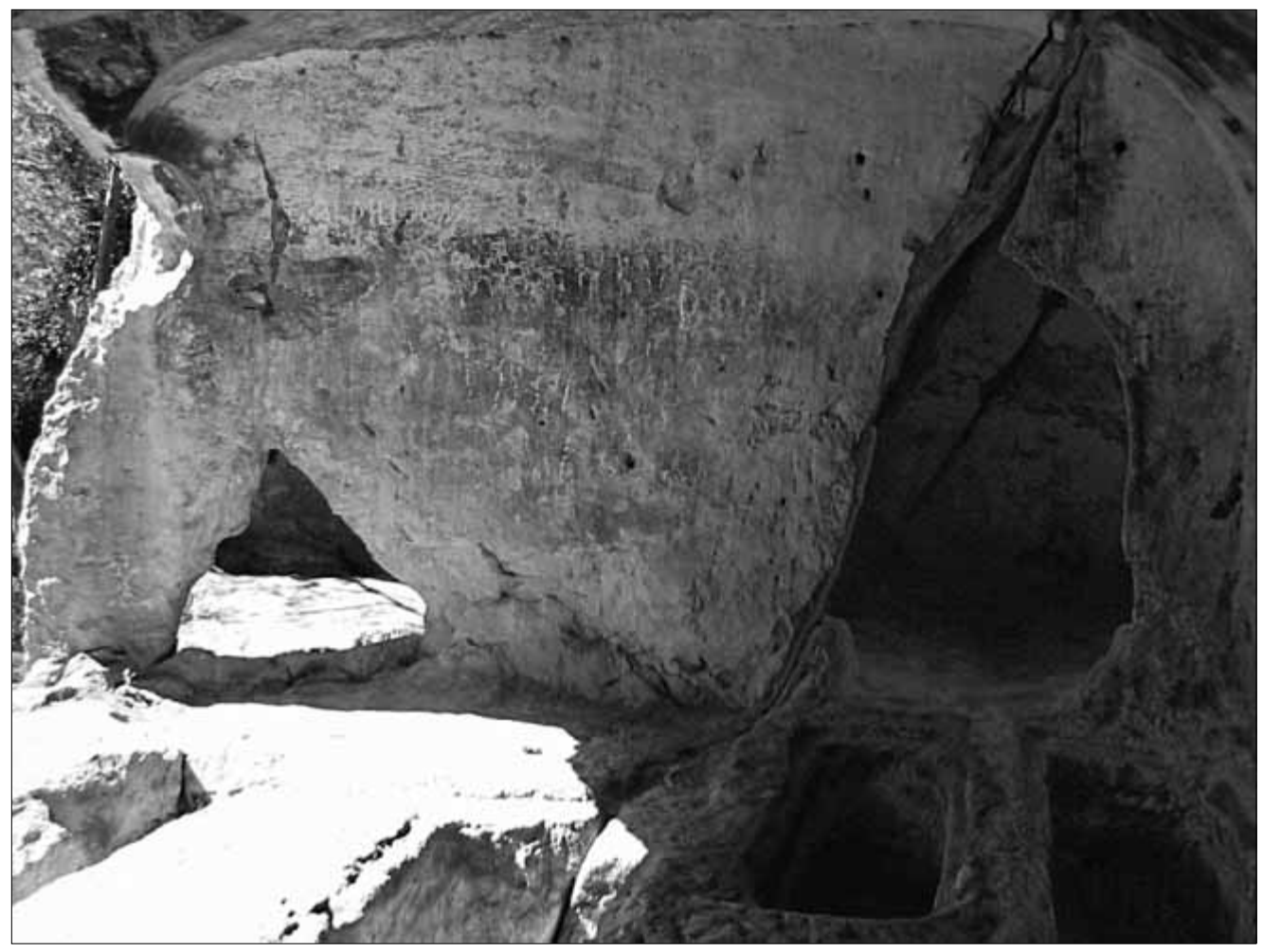

Lam. 2. Cueva de Las Gobas 6 (Laño), en Treviño. 


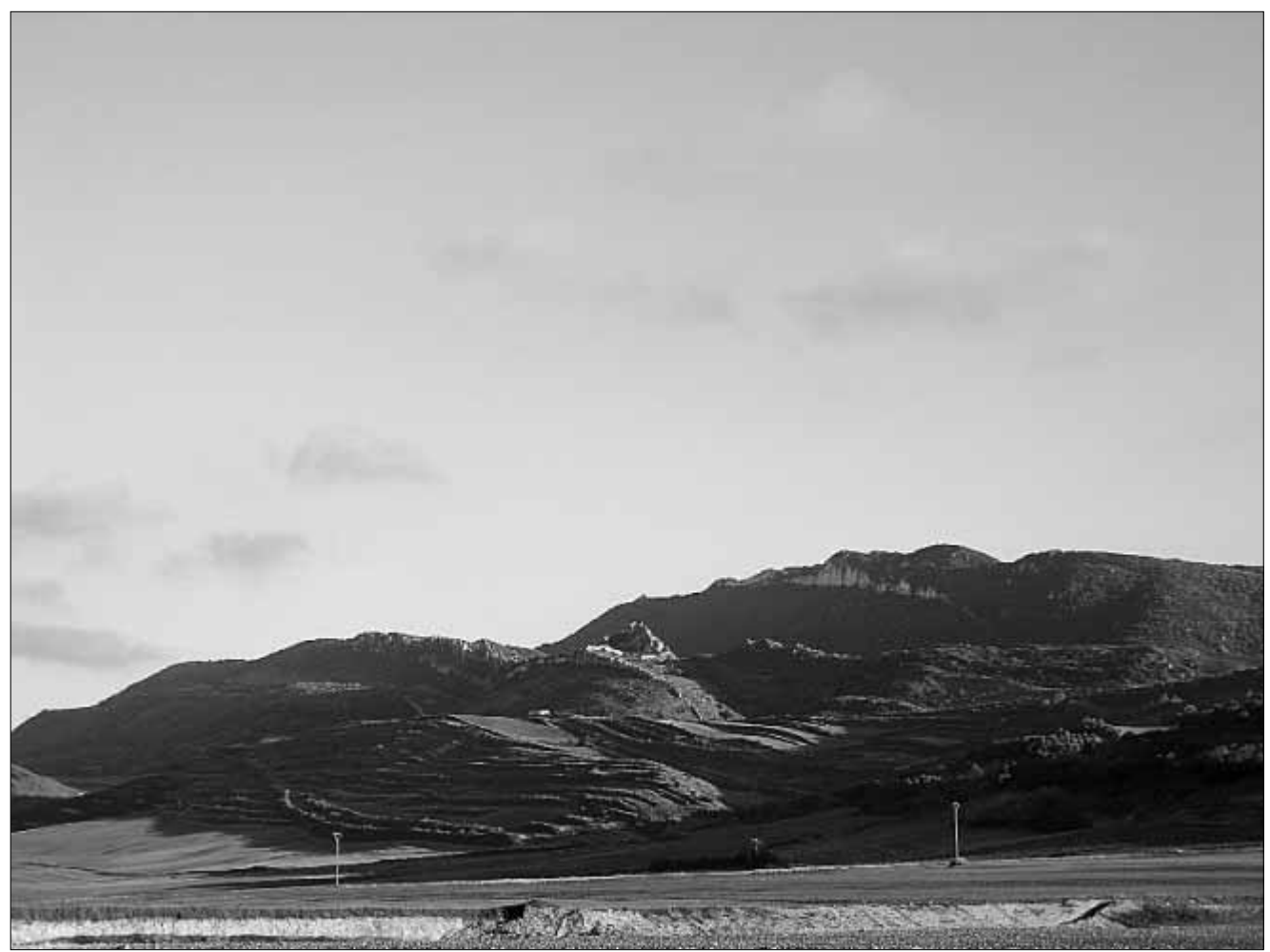

Lam. 3. Ubicación del castillo de Portilla (Zambrana, Álava).

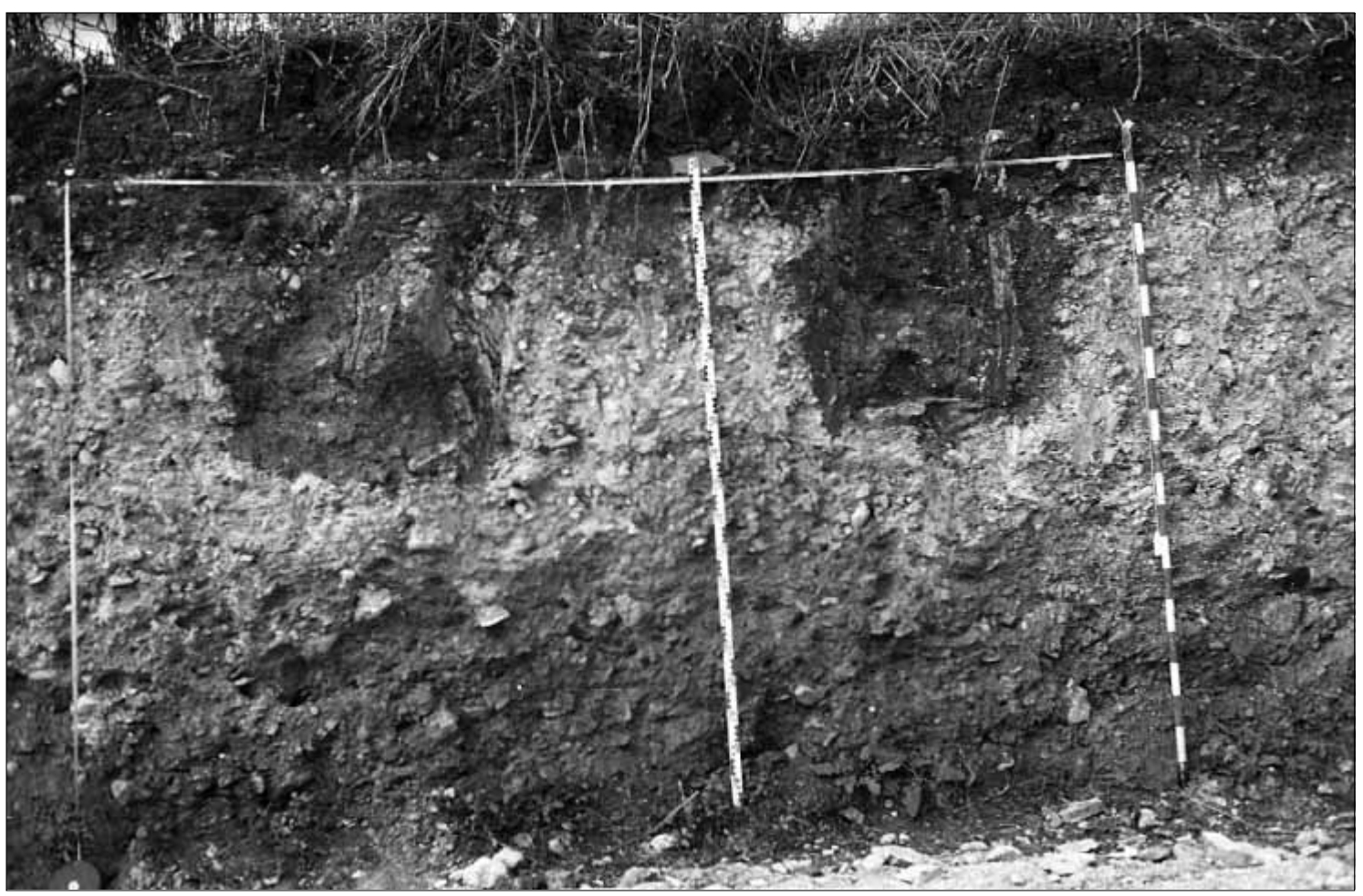

Lam. 4. Silos altomedievales excavados en Mendiola (Vitoria-Gasteiz), por P. Sáenz de Urturi. 


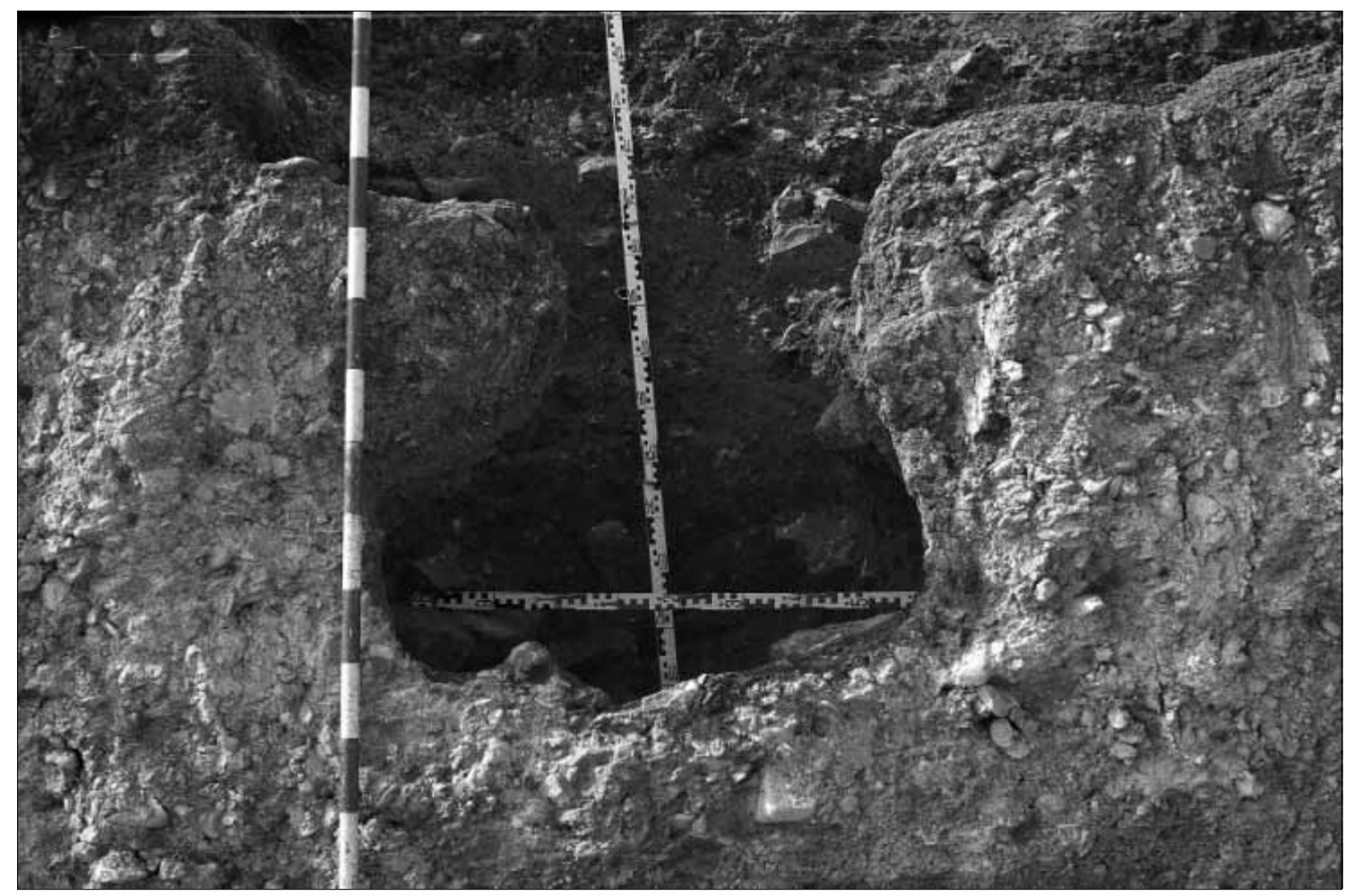

Lam. 5. Excavación de uno de los silos de Mendiola (Vitoria-Gasteiz), por P. Sáenz de Urturi.



Lam. 6. Silo excavado en proximidad de la iglesia de Salinillas de Buradón, por B. Bengoetxea Rementeria. 


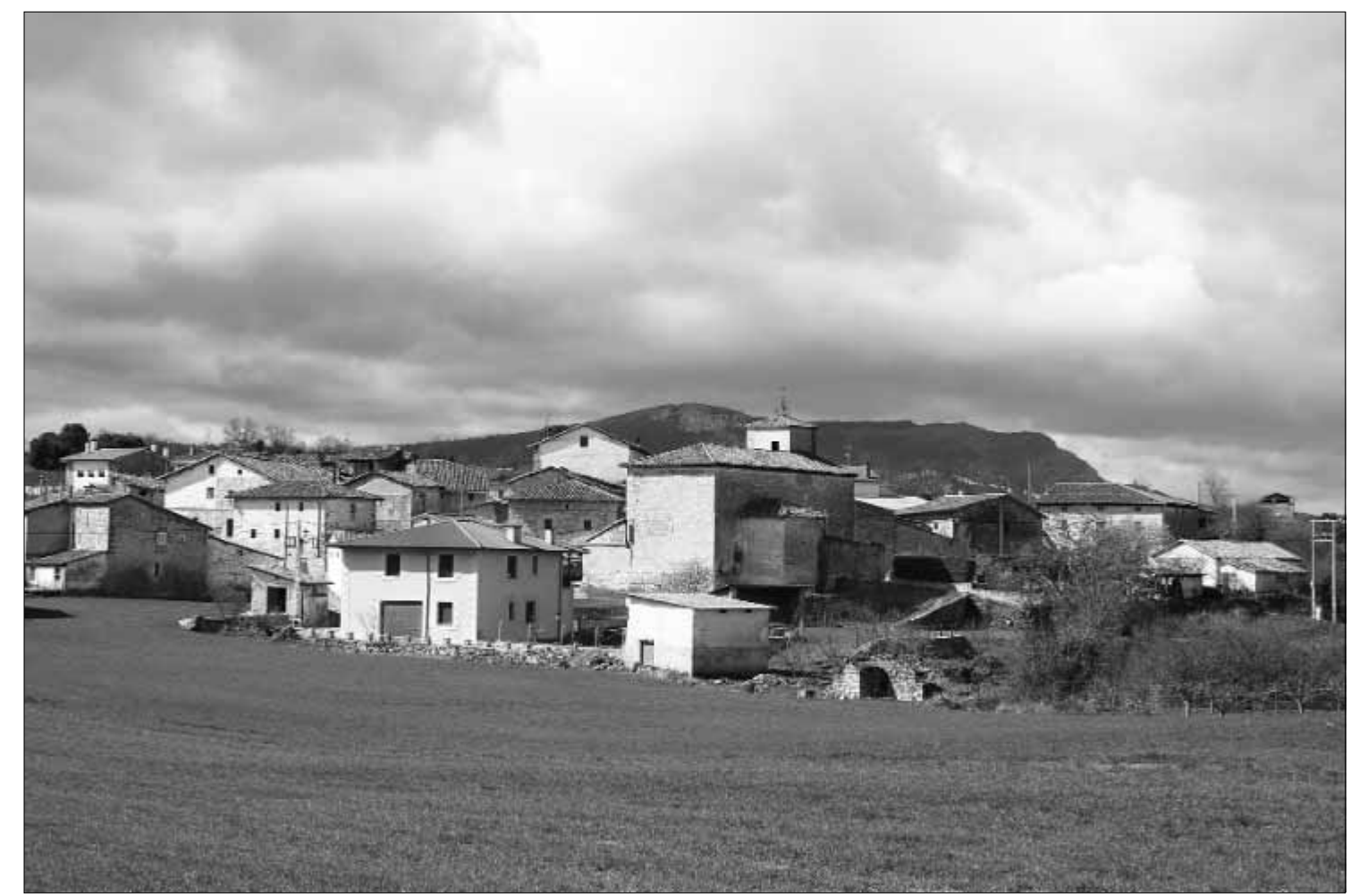

Lam. 7. Pueblo de Alcedo en la actualidad.

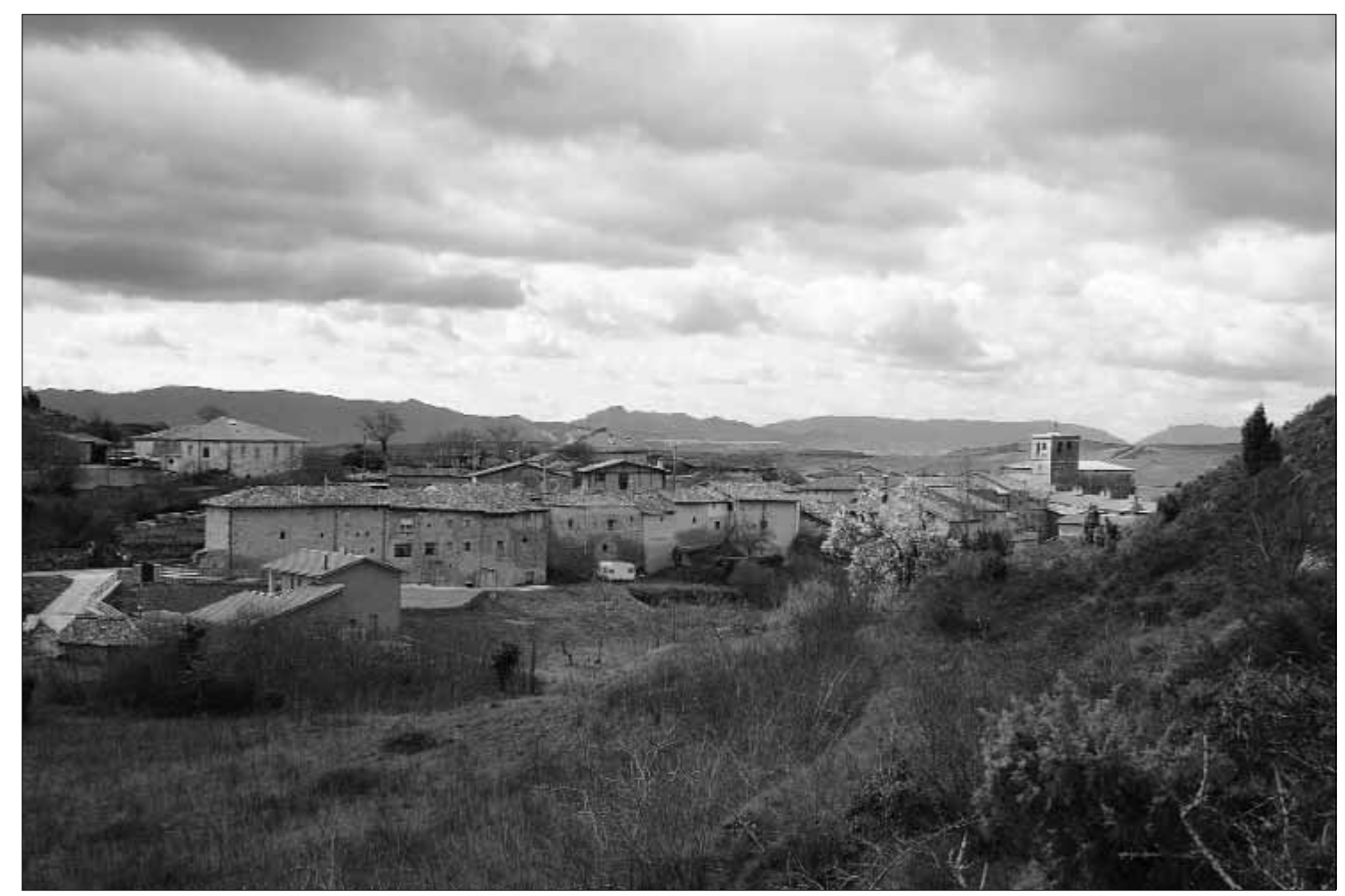

Lam. 8. Pueblo de Estavillo, documentado en el siglo IX. El conjunto de silos de Mavilla se encuentra en el extremo oriental del mismo. 




Lam. 9. Castillo de Henayo (Alegria-Dulantzi), donde se ha localizado los restos

de una ocupación prerromana y altomedieval. A sus pies se localiza el yacimiento romano de Angostina. 